\title{
The Chemistry of Ynol and Thioynol Ethers
}

Vincent James Gray* and Jonathan D. Wilden*, Department of Chemistry, University College London, 20 Gordon Street, London, WC1H OAJ, UK

\begin{abstract}
Alkynyl ethers and alkynyl thioethers ('ynol ethers' and 'thioynol ethers') are appealing building-blocks in synthetic chemistry due to their ease of manipulation and predictable reactivity. Until recently however, their potential has remained underexploited due to difficulties in preparation and isolation. Although recent advances in synthetic chemistry have highlighted various applications for ynol ethers, the equivalent thioynol examples have been rather less exploited despite a unique and fascinating reactivity profile. Although superficially the chemistry of alkynyl ethers and their sulfide counterparts are similar, close examination of their chemistry reveals important differences which can be exploited by the synthetic chemist.

This review will examine the preparation of both classes of compound and examine their reactivity to highlight their powerful synthetic applications. Particular focus will be made of thiynol ethers whose chemistry exhibits some fascinating differences compared to their oxygen counterparts and have immense untapped potential for synthetic chemistry.
\end{abstract}

\section{Author Biographies}

Vincent Gray obtained his MChem from the University of Bristol in 2009, undertaking a fourth year research project in asymmetric epoxidation supervised by Dr. Eoghan McGarrigle. He consequently moved to University College London where he obtained his Ph.D. in 2014 supervised by Dr. Jonathan Wilden. His Ph.D. focussed on the use of sulfur-based leaving groups in synthesis as well as developing new mechanistic rationale in describing novel chemical reactions. He next undertook a postdoctoral position with Prof. Erik Årstad at UCL, directed towards the synthesis of novel sulfonium salts for

${ }^{18} \mathrm{~F}$-labelling whilst working part time as a mass spectroscopy technician within the department. In 2015 he returned to the Wilden group as a research associate, developing and patenting a new route towards novel $\alpha$-amino sulfonamides. He was the recipient of the Peer Prize at the Royal Society of Chemistry organic section poster competition in 2012 as well as the Ramsay Medal in 2013.

Jonathan Wilden is currently senior lecturer in organic chemistry at University College London and from 2005 was lecturer at the same institution. Previously he worked as a postdoctoral research associate with Professor S. Caddick both at the University of Sussex and at UCL. He obtained a double 
honours degree in chemistry and biochemistry at the University of Southampton where he also obtained a PhD, focused on the synthesis of the marine natural product pseudopterosin, under the supervision of Professor David Harrowven. Research in the Wilden group is currently directed towards the development of new synthetic methods and elucidating their mechanisms.

\subsection{Introduction}

Ynol ethers and alkynyl thioethers serve as versatile building blocks in organic synthesis, allowing for a range of useful molecular architectures to be generated. The electron-rich nature of the alkyne motif in both classes of molecule allows for the unique reactivity features to be exploited in a range of $\mathrm{C}-\mathrm{C}$ bond-forming reactions. ${ }^{1}$ Ynol ethers in particular have been shown to possess a broad range of reactivity that can be exploited in the synthesis of complex molecules in order to gain access to otherwise difficult compounds whose preparation would be difficult or cumbersome via classical methods. ${ }^{2}$ Both ynol ethers and alkynyl thioethers possess similarities in reactivity, given the polarised nature of the electron rich double bond. For example, this reactivity was recently exploited by Tan and $\mathrm{Zhu}^{3}$ et al. in a regioselective oxyarylation reaction to form a range of useful $\alpha$-arylated products from both the ynol ether and alkynyl thioether (Scheme 1.0).

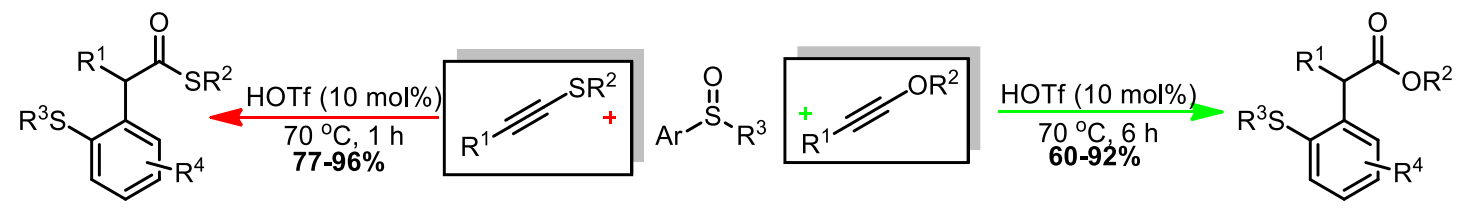

\section{Scheme 1.0}

\subsection{Ynol ether synthesis- Early methods}

The past thirty years have shown a slow but steady increase reports of new synthetic methods towards ynol ethers. Greene et $a l^{4}$ showed that a range of ynol ethers could be prepared in good yield via the dehalogenation of trichloroethylene. This classic method has been a benchmark synthesis towards ynol ethers and is most commonly used to prepare such compounds on a large scale (Scheme 2.0).

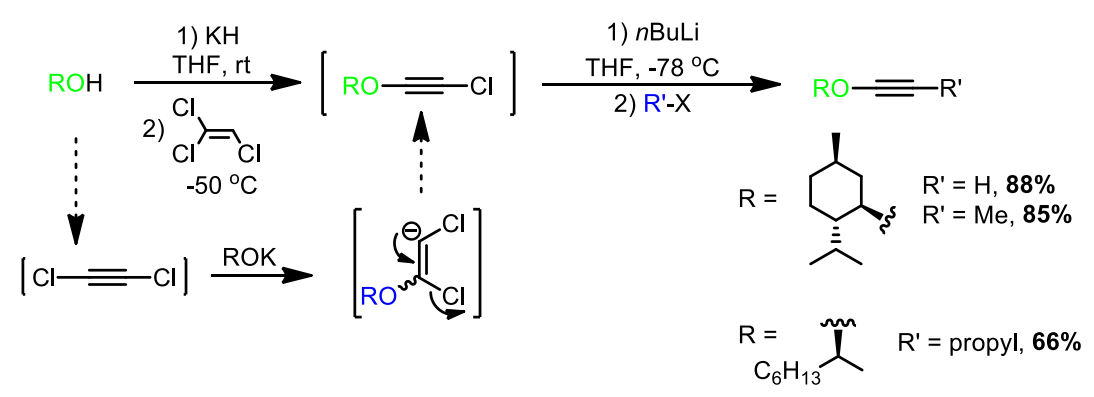

Scheme 2.0 
Himbert et al. ${ }^{5}$ have also harnessed the properties of trichloroethylene as a useful substrate in the synthesis of dichloro(alkoxy)ethenes (ynol ether precursors). Treating trichloroethylene with sodium alkoxide followed by $n$ BuLi promoted elimination and lithiation of the acetylide, allows for Pdmediated cross-coupling to yield aromatic alkynyl ethers. This reaction broadens the scope of the Greene approach and is a convenient method of manipulating the reactivity of the lithiated acetylide (Scheme 2.1).

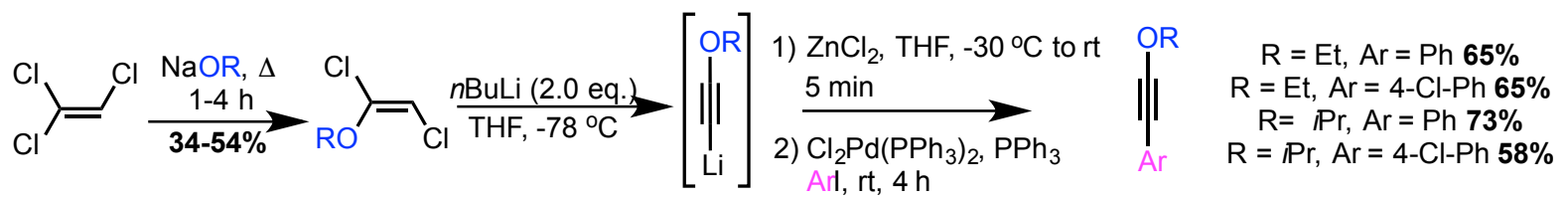

\section{Scheme 2.1}

In terms of dehalogenation-based approaches, Nakai et al. ${ }^{6}$ have utilised trifluoroethanol as a cheap building block in order to generate a range of ynol ethers in good yield (Scheme 2.2). This synthesis can be carried out in a single operation starting from routinely prepared ethers of trifluoroethanol followed by successive eliminations of HF and LiF.

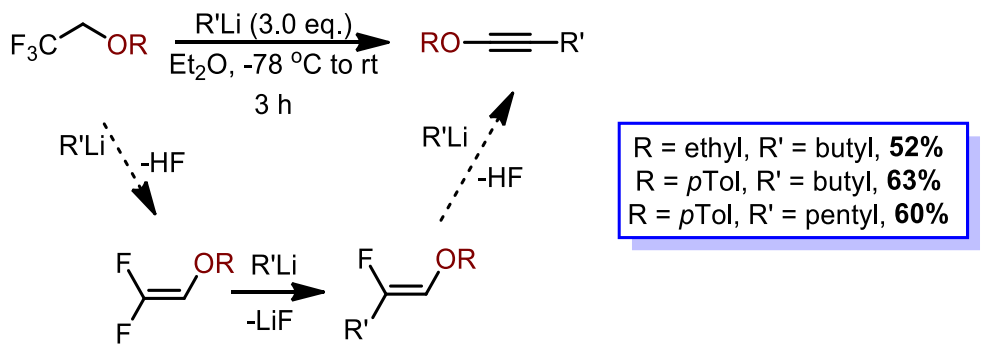

\section{Scheme 2.2}

\section{Ynol ether synthesis- Modern methods}

More recent advances towards ynol ethers have been developed by Minehan et al. In 2008 his group described a mild synthesis towards a range of these compounds. ${ }^{7}$ Primary, secondary and tertiary alcohols can be successfully employed in this synthesis to yield a range of ynol ethers starting with $\alpha$ diazoketones (Scheme 2.3) forming the $\alpha$-ketoether. Enolate formation, triflation and base promoted elimination then yields the ynol ether. Although employing a diazoketone as the starting material is less than ideal, this three-step protocol provides the products in good yield with both aromatic and aliphatic groups tolerated. 


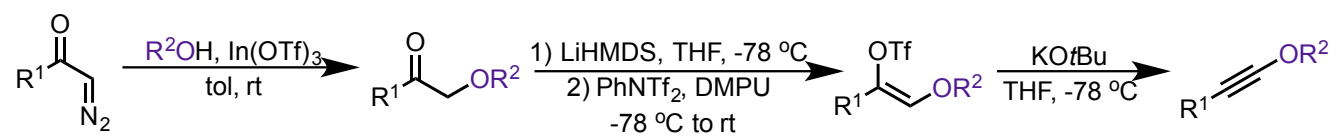

Selected Examples:
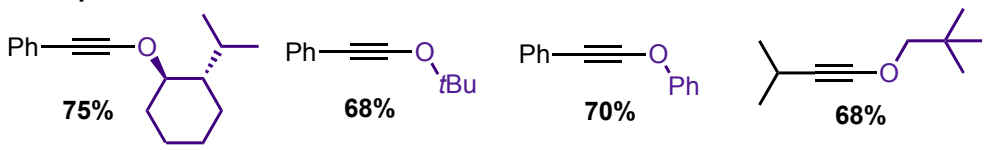

Scheme 2.3

Synthetic routes to terminal ynol ethers are limited due to their volatility and reactivity. However, one synthesis that affords a high yield of tert-butoxyethyne was developed by Pericàs et al. ${ }^{8}$ as outlined in Scheme 2.4. Although a lengthy process to reach the vinyl bromide ether precursor, this synthesis of tert-butoxyethyne can be achieved on approximately $30 \mathrm{~g}$ scale, allowing for a range of further transformations to be accomplished (Scheme 2.4).

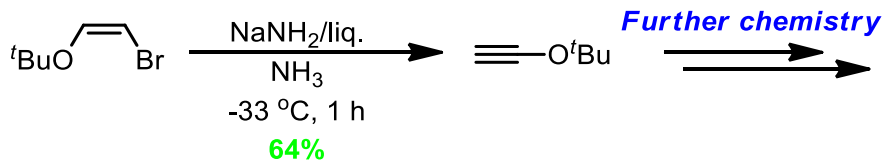

Scheme 2.4

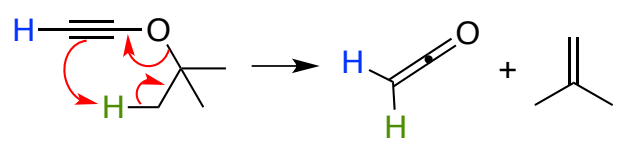

Figure 1

In common with other unsaturated tert-butyl ethers, this ynol ether is prone to rearrangement. In this case an intramolecular ene-reaction occurs even at room temperature, generating ketene (Figure 1). As such, this species must be prepared and stored at $-20{ }^{\circ} \mathrm{C}$. Nevertheless, this reactive, potentially useful compound may allow for an array of further modifications via deprotonation and nucleophilic attack, or, metal-mediated coupling reactions.

Evano et al. adopted a copper-catalysed coupling between an alcohol and a gem-dibromoalkene to access bromo-enol ethers. These compounds could be cleanly transformed to the corresponding ynol ether in the presence of potassium tert-butoxide (Scheme 2.5).$^{9}$ Only aromatic alcohols are tolerated in this reaction and the authors comment that dimerisation of the gem-dibromolefin occurs when aliphatic alcohols are employed. Overall, this synthesis furnishes a range of ynol ethers in good yield and with reasonably good scope. 


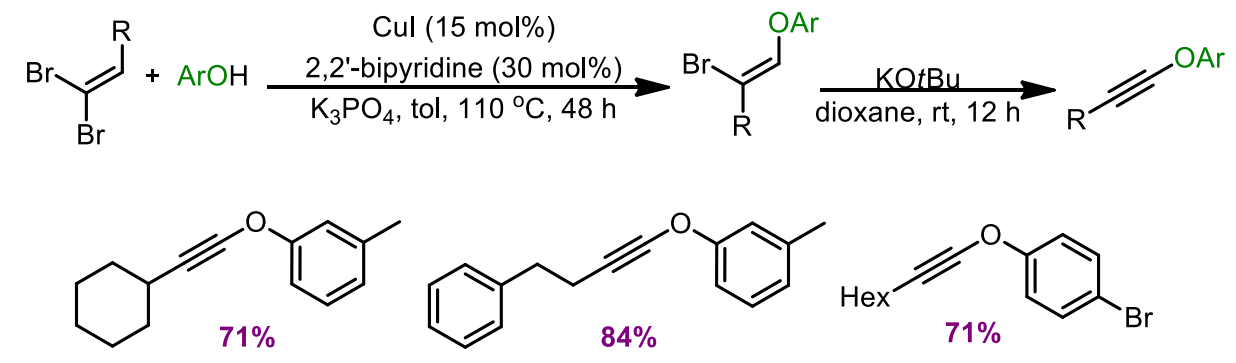

Scheme 2.5

In 2012, Wilden et al. ${ }^{10}$ published a new method towards ynol ethers that avoids the use of transition metals or any expensive reagents. This reaction relied on the use of an electron-withdrawing alkynyl sulfonamide, which, upon treatment with a potassium alkoxide in DMF, would rapidly allow for conversion to the corresponding ynol ether (Scheme 2.6).

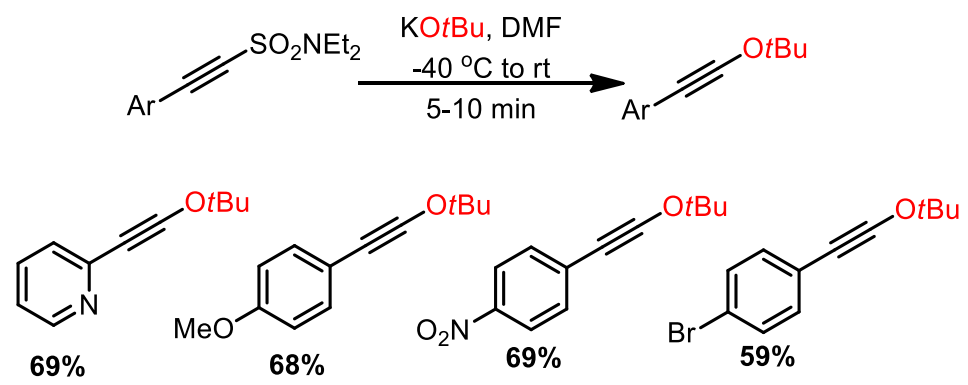

\section{Scheme 2.6}

By generated potassium alkoxides in situ, the group also showed that a range of primary and secondary alcohols could be used to synthesise ynol ethers with greater scope (Scheme 2.7). ${ }^{11}$ In this instance it was found that employing dimethylamine in THF was of great benefit as the reaction was complete in a matter of minutes.

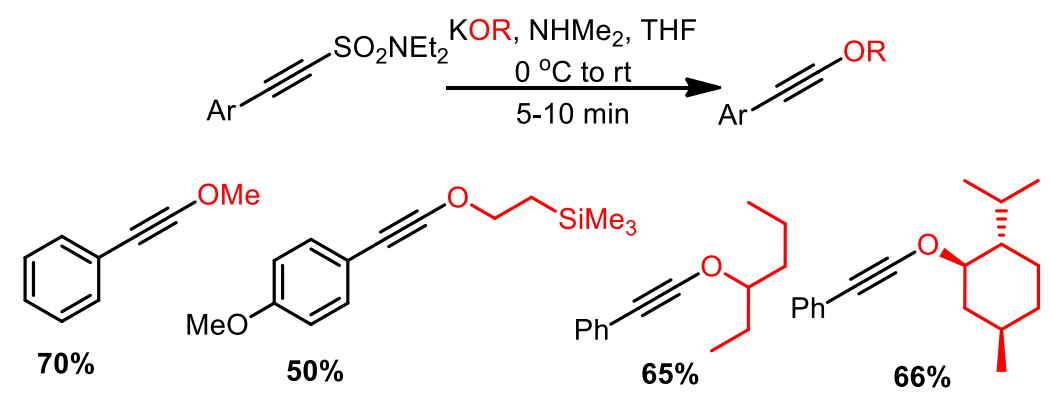

Scheme 2.7

Given the curious nature of this reaction, further investigation led Wilden et al. to hypothesise that this reaction involves a single electron transfer process to form a vinyl radical ion, followed by radical recombination and finally elimination to yield the ynol ether (Scheme $\mathbf{2 . 8}$ ). 


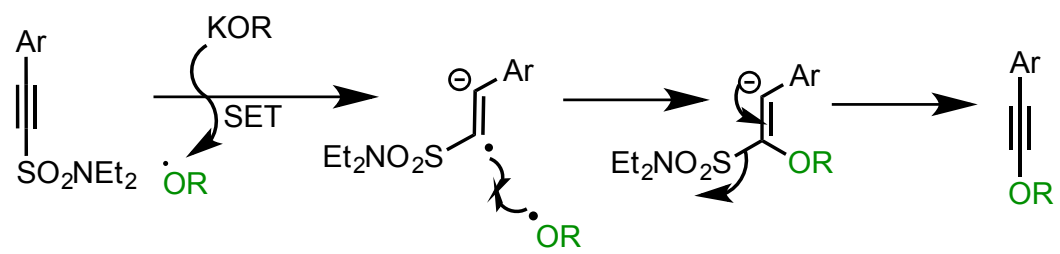

Scheme 2.8

In a similar fashion, García Ruano et al. later showed ${ }^{12}$ that the analogous alkynyl sulfones were also good substrates for the formation of ynol ethers upon treatment with potassium tert-butoxide. In this report, García Ruano et al. suggest that the potassium cation coordinates an oxygen on the $\mathrm{SO}_{2}$ group of the alkynyl sulfone, allowing the tert-butoxide anion to attack the $\alpha$ carbon via an Anti-Michael addition process. The intermediate vinyl anion can then eliminate the $-\mathrm{SO}_{2} \mathrm{Tol}$ group to furnish the product in good yield (Scheme 2.9).

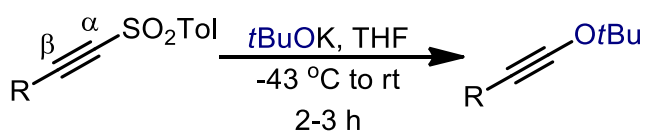

Scheme 2.9

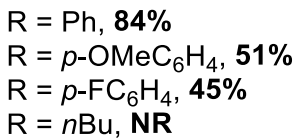

\subsection{Applications of Ynol Ethers}

The past thirty years has shown a marked increase in the use of ynol ethers as viable reactants in the synthesis of useful molecules. Pericàs et al. reported ${ }^{13}$ that tert-butyl ynol ethers are a useful source of ketene which can be used in a number of other cycloaddition reactions. For example, when tertbutoxyethyne is gently warmed, a retro-ene reaction will occur, allowing for ketene to react with another molecule of tert-butoxyethyne to afford a cyclobutenone via a [2+2] cycloaddition process. Further treatment with TFA can then lead to useful symmetrical di-ketones (Scheme 3.0).

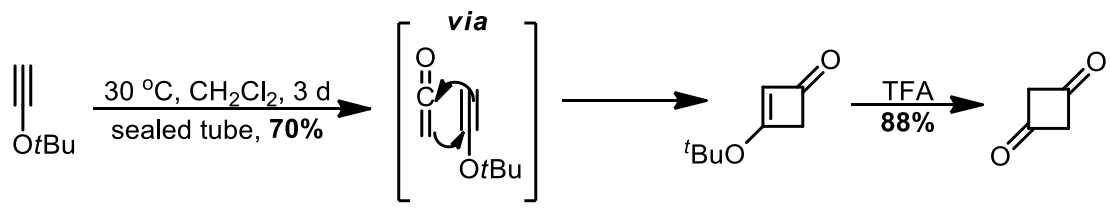

\section{Scheme 3.0}

Ready et al. ${ }^{14}$ were able to utilise tert-butoxyethyne as a ketene surrogate in a highly efficient Sonogashira cross-coupling reaction to form a range of aromatic ynol ethers which could be trapped in situ with a large rage of nucleophiles as well as undergoing cycloadditions in a single operation. This new development also allowed for the formation of quinolines in good yield (Scheme 3.1). 


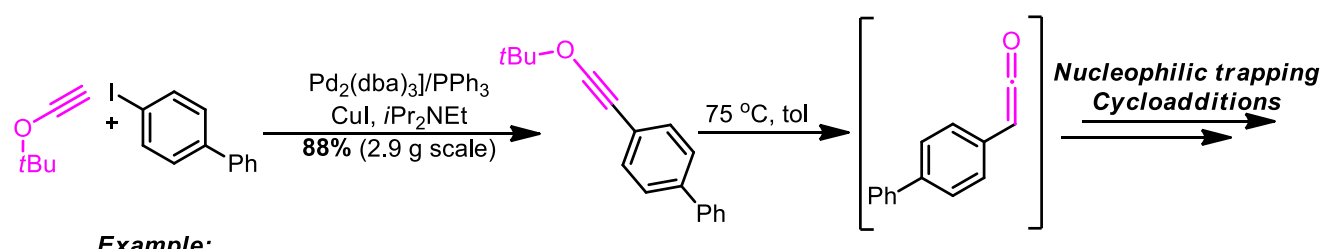

Example:

1) $\left.\mathrm{Pd}_{2}(\mathrm{dba})_{3}\right] /(2-\mathrm{Furyl})_{3} \mathrm{P}$

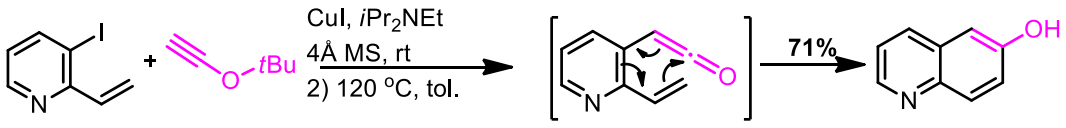

Scheme 3.1

Also harnessing the versatile properties of terminal ynol ethers were Davies et al. ${ }^{15}$ who developed a three-component reaction for the $\alpha$-aminoacylation of electron-rich indoles and pyrroles, which resulted in the regioselective introduction of four new bonds into the ynol alkyne backbone in good yield (Scheme 3.2).
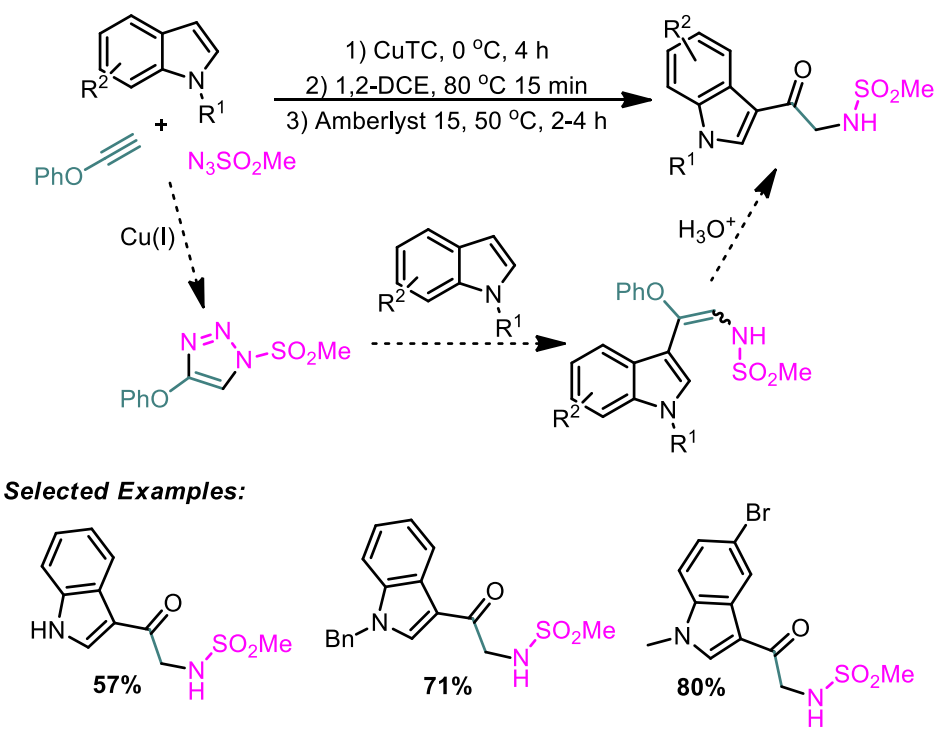

\section{Scheme 3.2}

Terminal ynol ethers also readily undergo metalation in situ which can act as very useful reactants, especially in diastereoselective reactions. Poisson et al. have studied the reactivity of metallated (both lithium ${ }^{16}$ and dimethylaluminium ${ }^{17}$ ) ethynyl ether anions with chiral $N$-sulfinyl imines, resulting in the synthesis of functionalized alkoxypropargyl sulfinamides in good yield and diastereoselectivity (Scheme 3.3). 


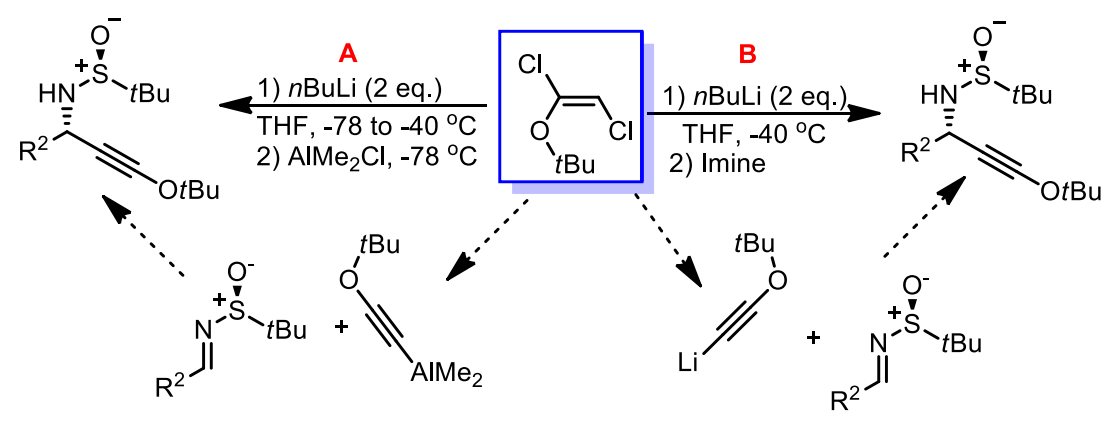

Scheme 3.3

In all instances, the alkynyl ether aluminium species (pathway A of Scheme 3.3) gave superior diastereomeric ratios. A comparison of both reactions comparing yields and diastereomeric ratio is given in Table 1.0.

\begin{tabular}{|c|c|c|c|c|c|}
\hline Entry & $\mathrm{R}^{2}$ & Yield (route A) & Yield (route B) & d.r. (route A) & d.r. (route B) \\
\hline $\mathbf{1}$ & $\mathrm{Ph}$ & $92 \%$ & $95 \%$ & $>98: 2$ & $88: 12$ \\
\hline $\mathbf{2}$ & $p-\mathrm{OMe}-\mathrm{C}_{6} \mathrm{H}_{4}$ & $77 \%$ & $91 \%$ & $>98: 2$ & $92: 8$ \\
\hline $\mathbf{3}$ & $p-\mathrm{NO}_{2}-\mathrm{C}_{6} \mathrm{H}_{4}$ & $90 \%$ & $56 \%$ & $97: 3$ & $54: 46$ \\
\hline $\mathbf{4}$ & $n \mathrm{Bu}$ & $83 \%$ & $84 \%$ & $97: 3$ & $85: 15$ \\
\hline
\end{tabular}

Table 1.0

Poisson et al. hypothesise that the aluminium gives greater d.r. values due to a six membered transition state forming in the presence of trimethylaluminium. Two equivalents of the aluminium acetylide allows for the activation of the imine (the nitrogen atom and an oxygen of the sulfoxide). The alkynyl ether unit can then be delivered through a chair transition state to give the products in excellent yield and diastereoselectivity.

Although their reactivity is at times difficult to control and harness, the synthesis of ketenes allows access to a range of heterocycles. With the knowledge that tert-butyl ynol ethers can undergo smooth retro-ene decomposition, Minehan et al. have shown that ketenes can be either trapped intramolecularly via cycloaddition ${ }^{18}$ or, attacked by nucleophiles ${ }^{19}$ to generate structures that would be otherwise difficult to access (Scheme 3.4). 


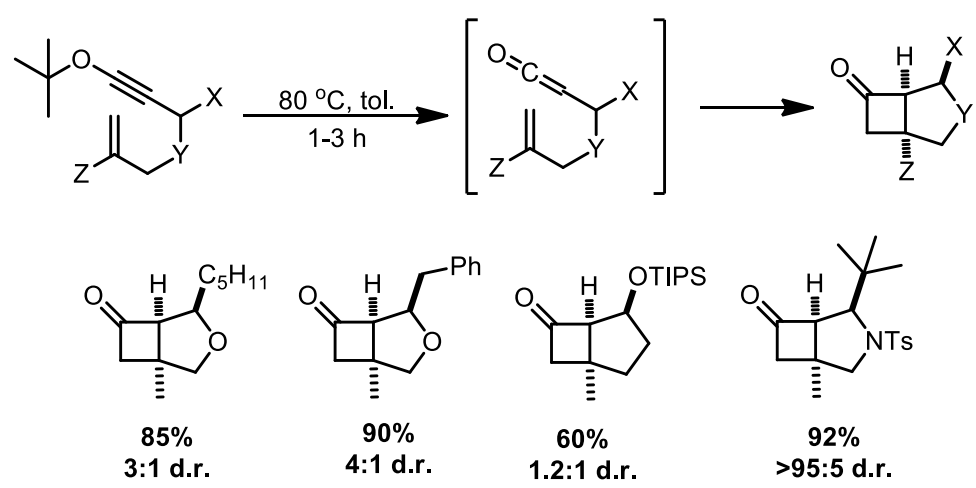

Scheme 3.4

Minehan et al. ${ }^{20}$ has shown that ynol ether-tethered dialkyl acetals participate in Lewis acid-catalysed rearrangements to afford alkoxycycloalkene carboxylates (Scheme 3.5). This reaction showcases the potential of exploiting the ynol ether moiety in generating novel ring systems, in a mild and expedient manner.

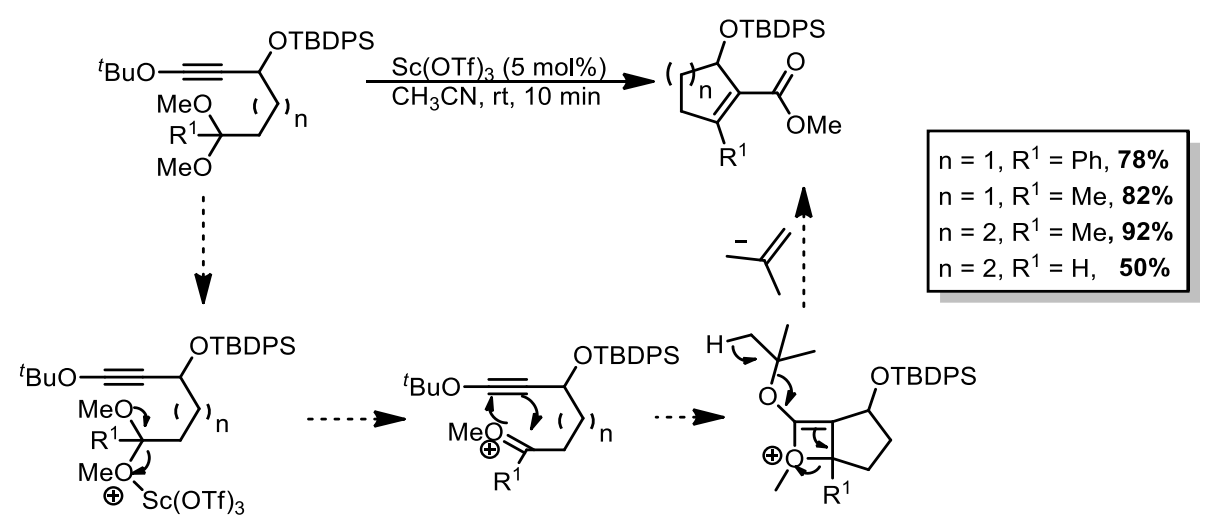

Scheme 3.5

Alkoxy alkynes have also seen use as masked acylating agents in amide bond formation. Danheiser et al. have employed ethoxyacetylene as a ketene surrogate in order to synthesise both macrocycle and linear amides. ${ }^{21}$ Common acylating agents include acid chlorides and mixed anhydrides, which are less atom-economical than ethoxyacetylene (the only leaving group being ethene in this case) (Scheme 3.6). 


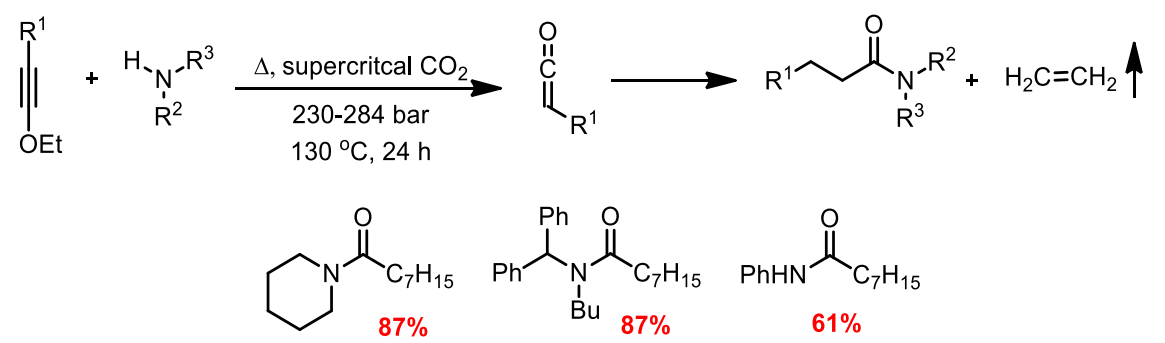

Further application:

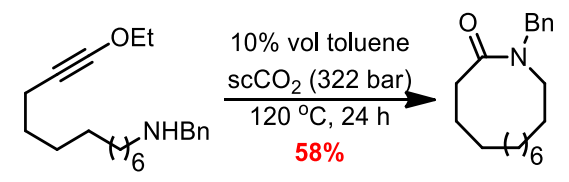

Scheme 3.6

More recently, Whitby et al. were able to trap ketenes with amines and alcohols via flow chemistry. This produced the corresponding amides and esters in good yield. By using inline IR spectroscopy they were able to monitor and optimise reactions more rapidly and safely than conventional means. ${ }^{22}$

Zhu et al. ${ }^{23}$ have also shown that ynol ethers can undergo haloallylation in the presence of a palladium catalyst to yield useful $\alpha$-chloro- and $\alpha$-bromoenol ethers. Consequently, these compounds can undergo Suzuki-Miyaura and Sonogashira reactions to afford substituted enol ethers in good yield. Hydrolysis of such compounds to give the ketone can also be achieved in excellent yield (Scheme 3.7).

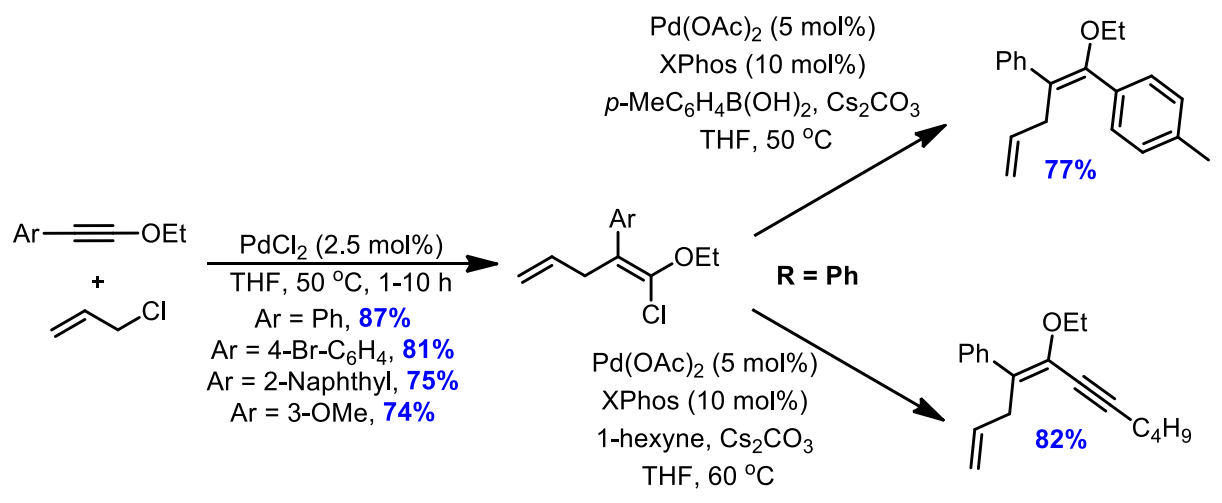

Scheme 3.7

Complementary to this approach, Zhu et al. ${ }^{24}$ have reported a palladium-catalysed addition of boronic acids to ynol ethers which allows for a regioselective addition of a range of groups to the $\alpha$ carbon on the ynol ether. This reaction results in the synthesis of a range of trisubstituted vinyl ethers in good yield and tolerates both aryl and alkenyl groups (Scheme 3.8). 

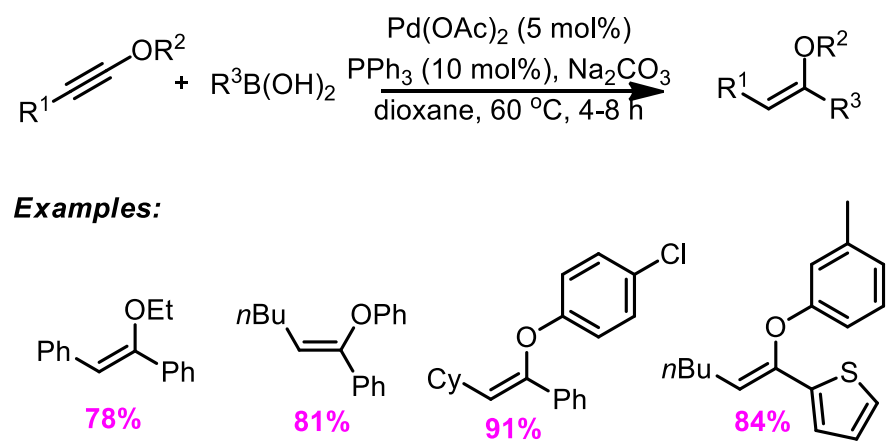

\section{Scheme 3.8}

Zhu et $a l .{ }^{25}$ have also successfully managed to switch the regioselectivity of addition to a ynol ether by employing a two-stage hydroboration/Suzuki-Miyaura coupling in order to gain access to $\beta, \beta$ disubstituted vinyl ethers, after studying work by Suzuki from the late 1980 's. ${ }^{26}$ Again, this methodology presents good yields and good substrate scope (Scheme 3.9)

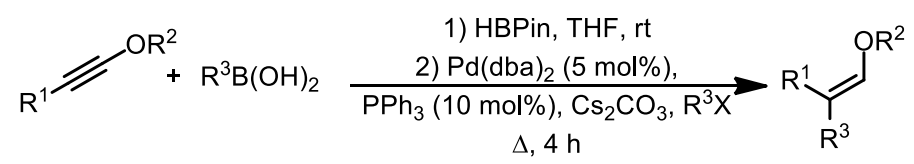

Examples:

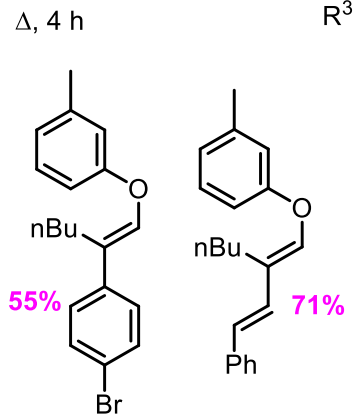

\section{Scheme 3.9}

Reddy et $\left.a\right|^{27}$ have reported a Pd-catalysed regio- and stereoselective synthesis of valuable 1,4-enyn3-ones via reaction of terminal alkynes with ynol ethers. This highly efficient reaction works well at room temperature and provides a range of useful compounds in high yield. Advantageously, the relatively cheap palladium complex $-\left[\mathrm{Pd}\left(\mathrm{PPh}_{3}\right)_{2} \mathrm{Cl}_{2}\right]$ proved to be highly efficient in catalysing the reaction without the need of a ligand (Scheme 3.10). 


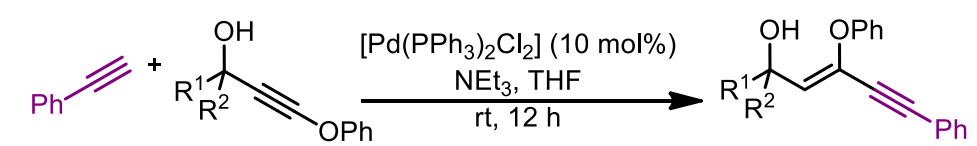

Selected Examples:<smiles>CC(C)(O)/C=C(/C#CC#Cc1ccccc1)c1ccccc1</smiles>

Scheme 3.10

Besides phenyl acetylene, many other terminal alkynes were also reported to be compatible under the same reaction conditions giving it greater scope and promise for future applications in constructing such molecules.

Due to their unique chemical and biological properties, fluorinated compounds are of widespread interest in the chemical community. With this in mind, Zhu et $a .^{28}$ have recently disclosed a novel fluorohalogenative reaction of ynol ethers to yield potentially useful $\alpha, \alpha$-fluorohalo esters. This useful reaction allows for the addition of three different groups $(\mathrm{F}, \mathrm{Br}$ and $\mathrm{I})$ as well as $\mathrm{OH}$ across the alkynyl ether triple bond in a regiocontrolled manner. This allows access to a range of useful di-halogenated compounds that would otherwise be more difficult to produce (Scheme 3.11).

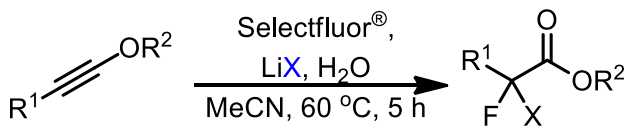<smiles></smiles><smiles>O=C(O[Hg]Cl)C(F)(Br)c1ccccc1</smiles><smiles>O=C(OS[AlH2])C(F)(Cl)C1CC1</smiles>

\section{Scheme 3.11}

The mild temperatures, relatively short reaction times and good yields makes this synthesis towards $\alpha, \alpha$-fluorohalo esters extremely useful. $\alpha, \alpha$-Difluoro esters are also successfully prepared when Selectfluor ${ }^{\circledR}$ is employed as the sole reagent in the reaction.

The reaction of 1,3-dipolar compounds with unsaturated systems is well known to be one of the most powerful methods of preparing five-membered rings. It is perhaps surprising therefore that $[3+2]$ cycloadditions have not been more widely reported with ynol ethers since the additional oxygen functionality lends an additional handle in the product for further manipulation (although, one example is given in Scheme 3.2). Nevertheless, Ready et al. ${ }^{29}$ reported the formation of highly substituted cyclopentanones via reaction of ynol ethers with functionalised cyclopropanes. In the 
presence of a Lewis Acid, the cyclopropane ring opens to form a Zwitterion which can then undergo a cycloaddition with a ynol ether (Scheme 3.12).
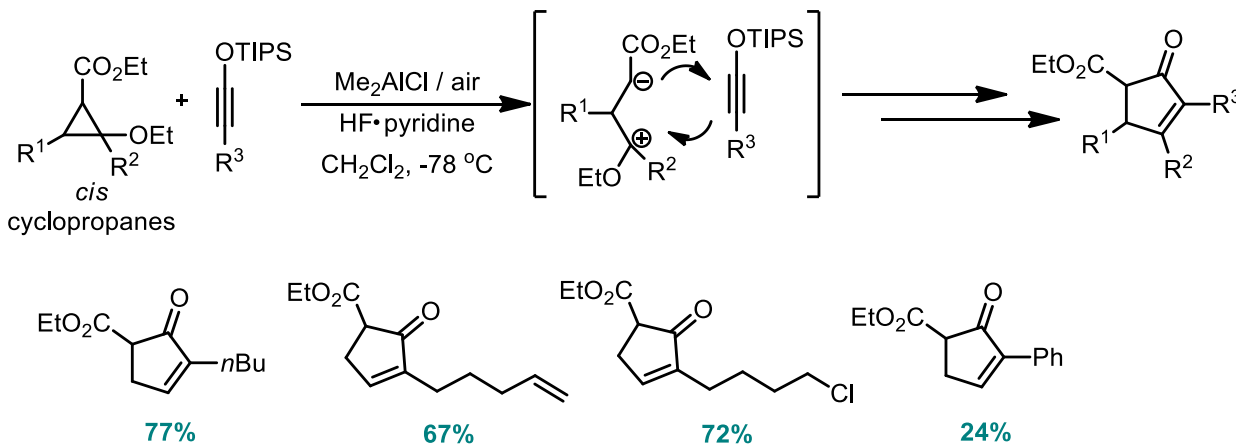

\section{Scheme 3.12}

Utilising the oxygen on an alkynyl ynol ether as a directing group, Minami and Hiyama et $a l^{30}$ were able to access substituted benzopyran frameworks via a $\mathrm{C}-\mathrm{H}$ activation/cycloaddition reaction. Consequently these products could be employed in further cycloaddition reactions to yield condensed polycycles (Scheme 3.13).
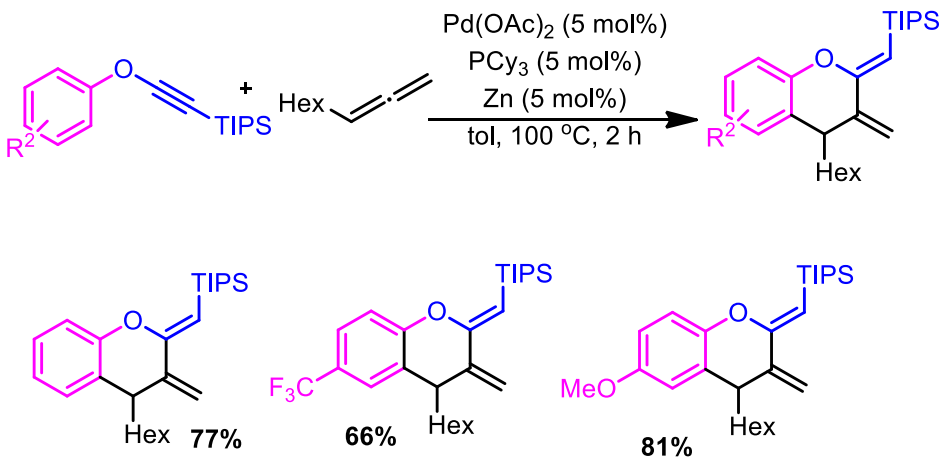

Scheme 3.13

O-Silyated ynol ethers have also proved valuable in medium ring synthesis. Li and sun et al. ${ }^{31}$ recently reported a catalytic ring expansion of cyclic hemiaminals to form a range of 7 and 8-membered cyclic lactams. Key to this reaction was the use of a tosyl protecting group on the nitrogen atom. Upon formation of the imine, the tosyl group increases its electrophilicity, allowing the silyated ynol ether to attack through the $\beta$-carbon atom (Scheme 3.14). 


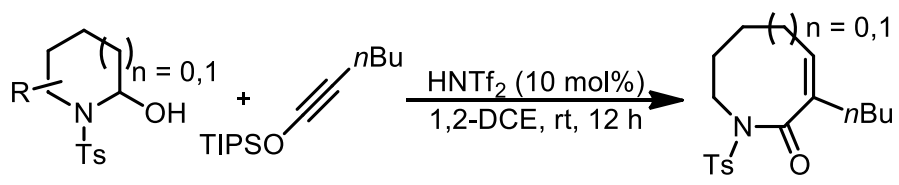

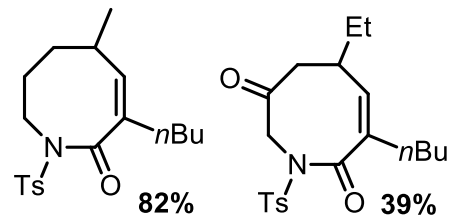

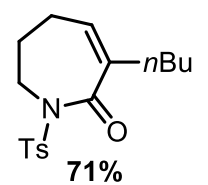

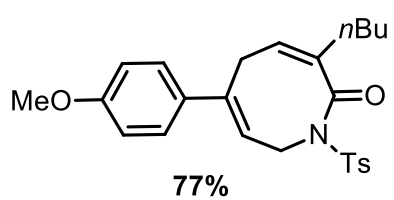

Scheme 3.14

\section{Synthesis and Applications of Metal Ynolates}

Having considered the reactions of ynol ethers, an interesting question arises as to the preparation and reactivity of ynolates. These species are the alkyne equivalent of enolates and, given the prevalence and significance of enolate chemistry to organic chemistry, a consideration of the ynolates is certainly warranted. As expected, ynolates are significantly more reactive than their ether counterparts but are nevertheless excellent substrates for a range of organic transformations. Given their reactivity, they are usually prepared in situ and consequently reacted with an appropriate substrate. An early example of ynolate synthesis was reported by Kowalski et $a l^{32}{ }^{32}$ who designed a single-step one carbon homologation of esters that proceeded via an ynolate intermediate (Scheme 3.15).

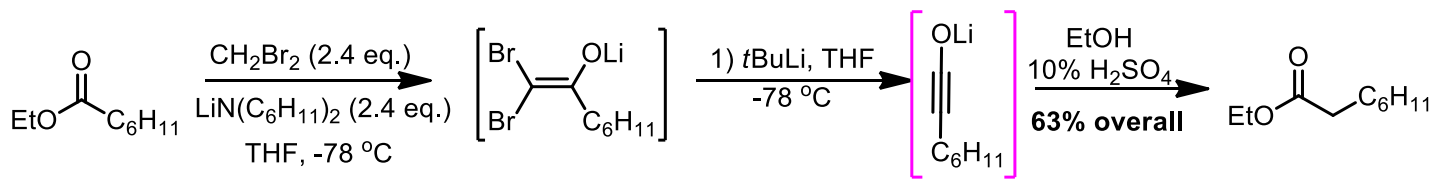

\section{Scheme 3.15}

This reaction can be regarded as the carbon analogue of the Hoffman rearrangement ${ }^{33}$ and is a much milder alternative to the Arndt-Eistert homologation ${ }^{34}$ which requires hazardous diazomethane.

Julia et al. $^{35}$ have also reported a rapid route towards lithium ynolates in situ, via oxygen transfer to an acetylenic carbanion. This route allows for the synthesis of a range of lithiated ynolates which can be isolated as the $O$-silylated derivative. Compared to other ynolate syntheses, this route is faster and much more atom economical (Scheme 3.16). 


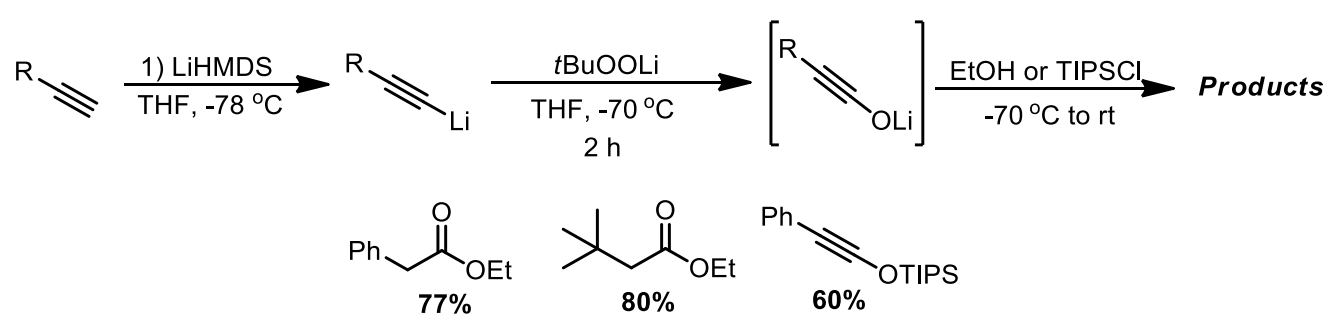

Scheme 3.16

Shindo et al. $^{36}$ have also exploited the high reactivity of ynolates by developing a tandem [2+2] cycloaddition-Dieckmann condensation to afford 2,3-disubstituted-2-cyclohexanones and pentanones regioselectively and in excellent yield (Scheme 3.17).

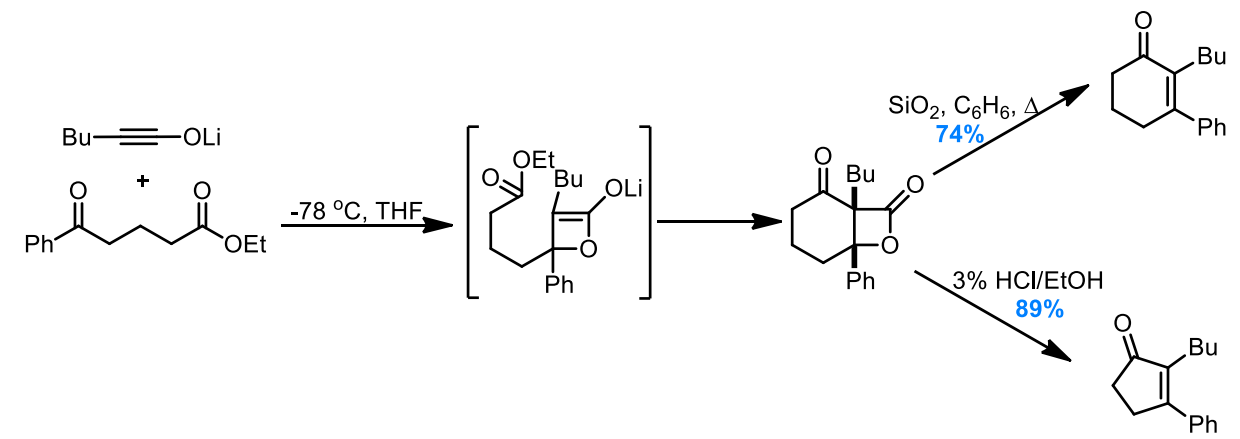

Scheme 3.17

Having outlined the chemistry of ynol ethers and ynolates in organic synthesis, it is worthy of note that the applications for which these species are wide and varied and yet this area of research is still relatively neglected. It is also striking that although these species are clearly reactive towards electrophiles, the reactions are only occasionally reminiscent of the typical reactions of their closest relatives; enol ethers and enolates. Although perhaps surprising, this leads us to suspect that there will be many more novel transformations employing these compounds in the years to come.

\subsection{Thioynol Ether Synthesis}

In recent years the number of reports in the chemical literature of the preparation of ynol ethers, ynolates, alkynyl phosphorus compounds and ynamides / ynamines has increased dramatically. It is surprising therefore that despite alkynyl thioethers serving as useful, reactive building blocks in organic synthesis, convenient methods towards their preparation are still somewhat lacking. The most general path for their preparation involves the deprotonation of a terminal alkyne, followed by reaction with an electrophilic sulfur unit. For example, MaGee et al. ${ }^{37}$ developed a high-yielding synthesis of a range of alkynyl thioethers via reaction of deprotonated alkynes with diphenyldisulfide (Scheme 4.0). 

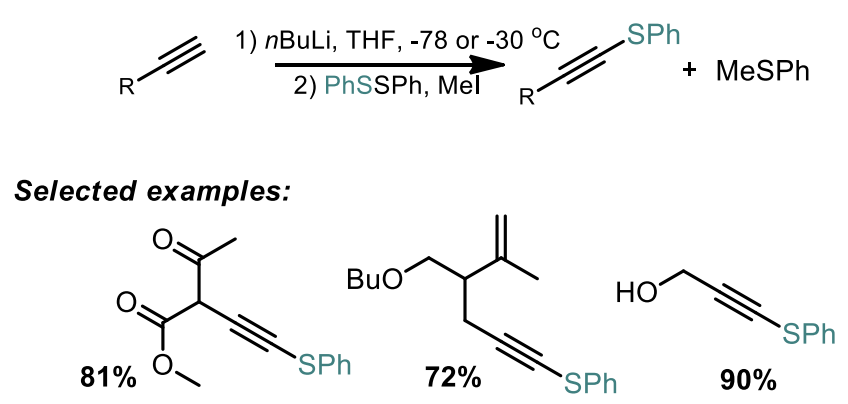

Scheme 4.0

The use of methyl iodide is important in this case as it is thought to $S$-alkylate the diphenyldisulfide, rendering it a superior electrophile in the reaction. The use of methyl iodide also ensures the MeSPh side product does not react with the desired product as the phenylthiolate anion is more nucleophilic. The use of a thiolate trap is critical in these reactions to ensure high yields. Tam et al. ${ }^{38}$ have shown that employing $p$-nitrobenzyl bromide is a good way to suppress further reaction of the desired alkynyl thioether (Scheme 4.1). Although an elegant solution to the problem, employing $p$ nitrobenzylbromide is clearly undesirable both in terms of toxicity and atom efficiency.

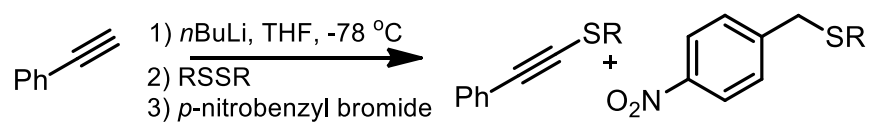

Selected examples:
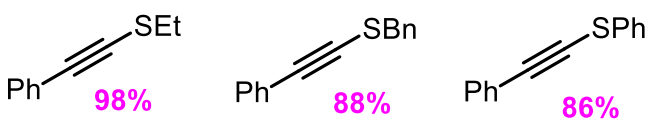

\section{Scheme 4.1}

Shibasaki et al. $^{39}$ have also shown that a combination of CuOTf and PhSSPh forms an excellent source of ' $\mathrm{PhS}^{+ \text {' }}$ which was used to form alkynyl thioethers in good yield (Scheme 4.2).

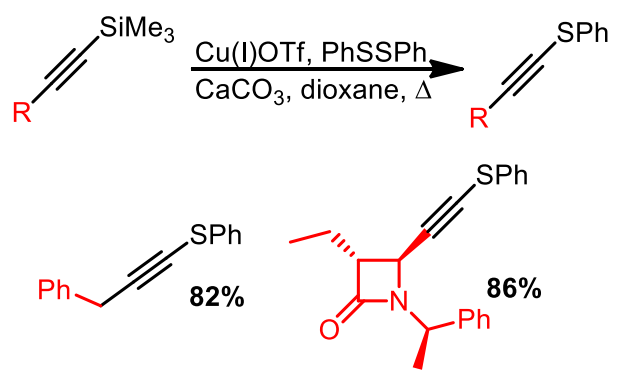

\section{Scheme 4.2}

A sound mechanistic rationale is also provided for this reaction. The authors hypothesise that the CuOTf allows for transient formation of $\mathrm{PhS}^{+}$which can add to the trimethylsilyl-protected alkyne. The 
highly reactive vinyl cation can then undergo elimination to form the target alkynyl thioether in good yield (Scheme 4.3).

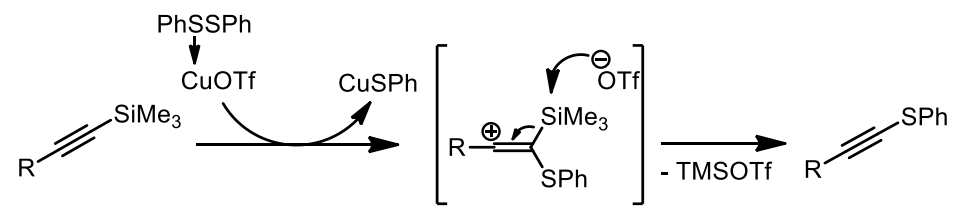

\section{Scheme 4.3}

This combination of reagents appears to not have been studied further since this 1990 publication which leaves a great deal of scope to be investigated.

Braga et al. $^{40}$ have also developed an approach to alkynyl thioethers using a copper(I) salt. In this case the starting material is an alkynyl bromide and HMPA is used as the solvent (Scheme 4.4).

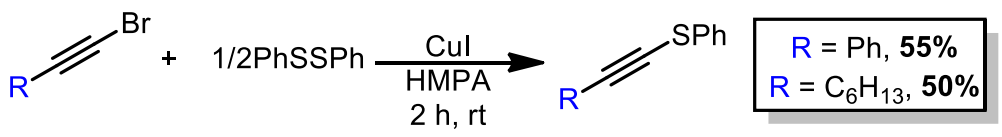

\section{Scheme 4.4}

Compared to the reaction reported by Shibasaki et $a{ }^{39}{ }^{39}$, these two requirements are not desirable as the starting material will usually need to be prepared by bromination of the terminal alkyne and HMPA is a rather toxic solvent. On the other hand, the reaction proceeds at room temperature in two hours in fair yield whereas Shibasaki's report requires long reflux conditions.

Also in the arena of copper(I) catalysis, Rioux et $a l .{ }^{41}$ have developed a facile route towards alkynyl thioethers using terminal alkynes and thiols. Advantageously, the relatively cheap, commerciallyavailable starting materials allows for the rapid synthesis of a wide range of alkynyl thioethers in high yield (Scheme 4.5).

$$
\mathrm{R}^{1} \equiv+\mathrm{R}^{2} \mathrm{SH} \frac{\mathrm{CuCl}(5 \mathrm{~mol} \%)}{\mathrm{KMSO}, \mathrm{O}_{2}, 70^{\circ} \mathrm{C}} \mathrm{R}^{1}=\mathrm{SR}^{2}
$$

Selected Examples:

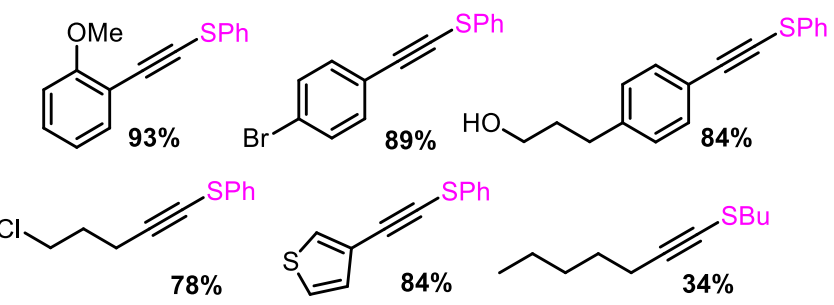

Scheme 4.5 
A wide range of functional groups, as well as both aromatic and aliphatic groups are tolerated in this reaction making it a very desirable method for the synthesis of alkynyl thioethers.

Similarly, Wilden et al. ${ }^{42}$ have utilised alkynyl chlorides in the synthesis of alkynyl sulfides. In this synthesis, it is postulated that the reaction proceeds via a radical anion intermediate. If the amine additive is removed, the reaction takes much longer to complete, suggesting that the amine aids an electron transfer process between the thiolate anion and the alkyne (Scheme 4.6).

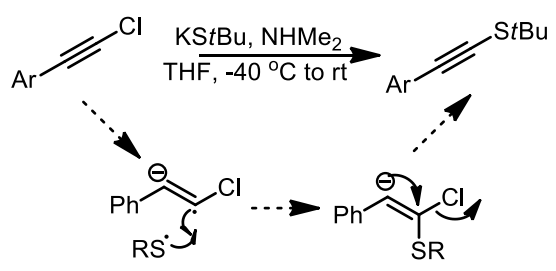

Selected Examples:

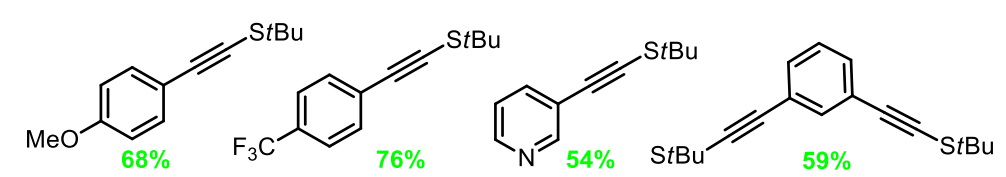

Scheme 4.6

In general, compared to other alkynyl thioether synthesis, this reaction is noteworthy as low temperatures are allowed for the reaction to proceed smoothly and in high yields without any transition metal catalyst.

Wilden et al. have also shown ${ }^{43}$ that alkynyl sulfonamides serve as excellent reactants in the synthesis of alkynyl thioethers. Similar to the alkynyl chlorides studied within the group, these electron deficient alkynes are hypothesised to be good electron acceptors thus stabilising radical anion intermediates which can then undergo radical recombination with a thiyl radical (Scheme 4.7). The drawback of this synthesis exists in the synthesis of the alkynyl sulfonamide which is cumbersome and relatively inefficient, since no satisfactory protocol for the generation of alkynyl sulfonamides currently exists.

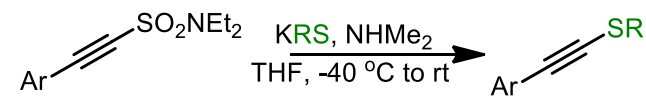

Selected Examples:

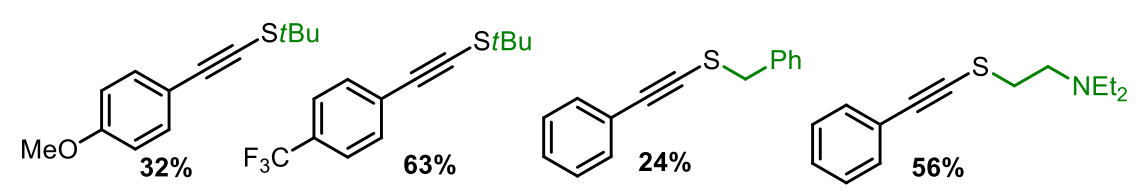

Scheme 4.7

In the field of composite materials, Matsuda et $a l .{ }^{44}$ were able to generate self-assembled monolayers of alkynyl thioethers on a gold surface. In the course of their work, they describe a synthesis of 
intermediate trimethylsilylethyl alkynyl thioethers as described in Scheme 4.8. These can be further manipulated to yield various other alkynyl thioethers by treatment with TBAF and subsequent trapping of the alkynyl thiolate anion in situ.

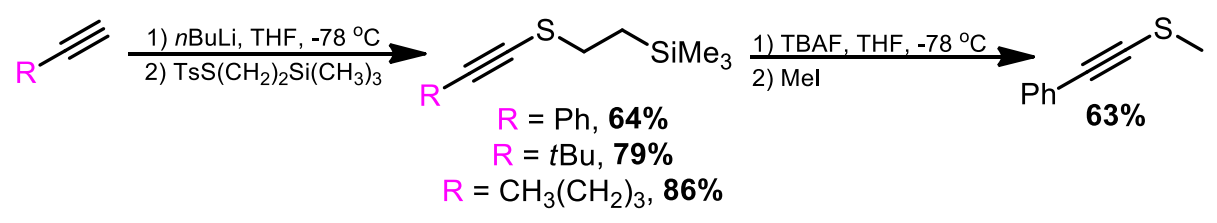

\section{Scheme 4.8}

A relatively inexpensive method for the synthesis of alkynyl thioethers was devised by Hu et al. $^{45}$ who demonstrated that elemental sulfur could be reacted with deprotonated alkynes and the consequent alkynyl thiolates trapped with a range of electrophilies (Scheme 4.9).

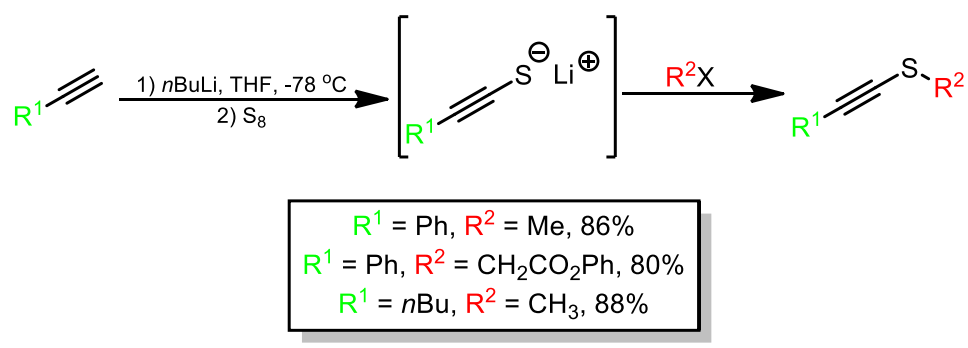

\section{Scheme 4.9}

The reaction is high yielding and can be achieved in a single operation, avoiding the use of odorous thiols.

More recently, Qing et al. $^{46}$ have shown that trifluoromethylthiolation can be easily achieved by using elemental sulfur and the Ruppert-Prakash reagent ${ }^{47}, \mathrm{CF}_{3} \mathrm{SiMe}_{3}$. This reaction is successful at room temperature and shows excellent substrate scope (Scheme 4.10).

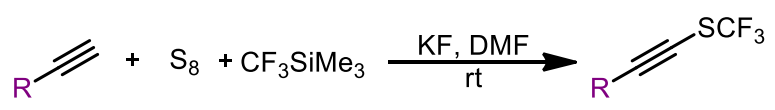

\section{Selected Examples:}

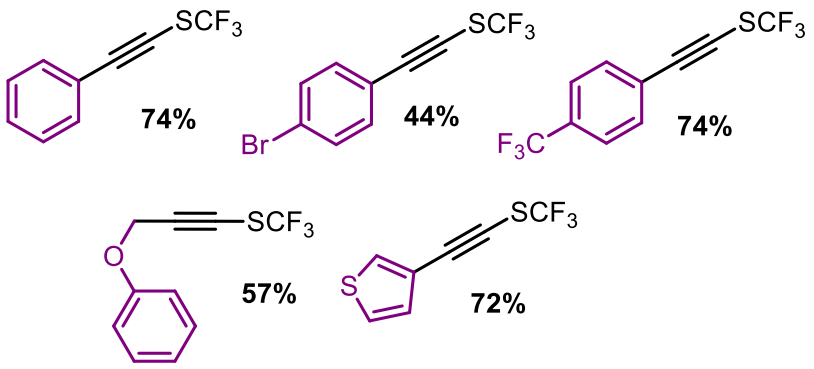

Scheme 4.10 
Based on their findings, it is suggested that $S_{8}$ is behaving as an oxidant in the reaction, generating the reactive $-\mathrm{SCF}_{3}$ anion which then reacts with phenylacetylene. A range of medicinally relevant and useful compounds can therefore by synthesised in a single operation.

Similar compounds can be generated with a slightly more complicated trifluoromethanesulfenate shown in (Scheme 4.11). Studies by Shen et al. ${ }^{48}$ have shown that terminal alkynes can react smoothly and in good yield in the presence of a copper(I) catalyst. Although the yields are lower compared to Qing, this synthesis avoids the use of the expensive Ruppert-Prakash reagent.
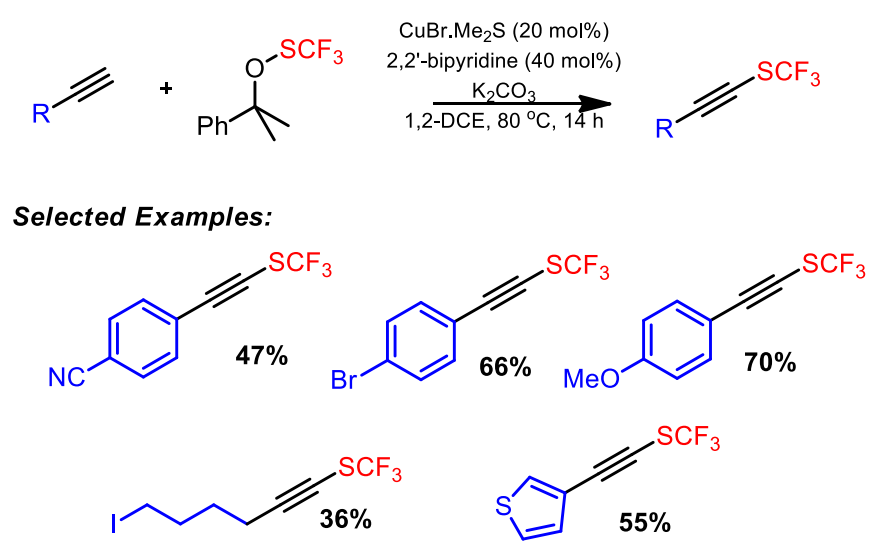

Scheme 4.11

As with many organic processes, eliminating transition or heavy metals in the synthesis of alkynyl thioethers would be of benefit as this may make the overall process cheaper and more environmentally-friendly. Pan et al. ${ }^{49}$ recently reported a method utilising gem-dibromoalkenes and substituted thiophenols (Scheme 4.12).

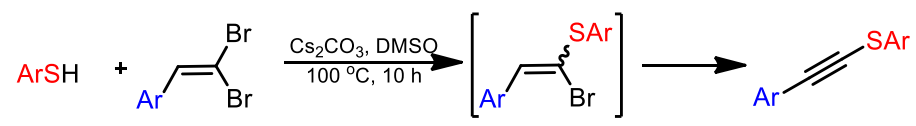

Selected Examples:<smiles>CSC#Cc1ccccc1</smiles><smiles>S=CSC#Cc1cccc2ccccc12</smiles><smiles>FC(F)(F)c1ccc(C#CC#Cc2ccc(Br)cc2)cc1</smiles>

Scheme 4.12

Although the conditions are rather forcing, this synthesis shows good scope with good yields and avoids the need for transition metals catalysis. 
Another fine example of transition metal-free alkynyl thioether synthesis was reported by Waser et $a .^{50}$ in 2014. In this case, a wide range of thiols could be reacted with an array of functionalised EBX reagents to gain access to a range of interesting and highly functionalised compounds including sugars and amino acids (Scheme 4.13).
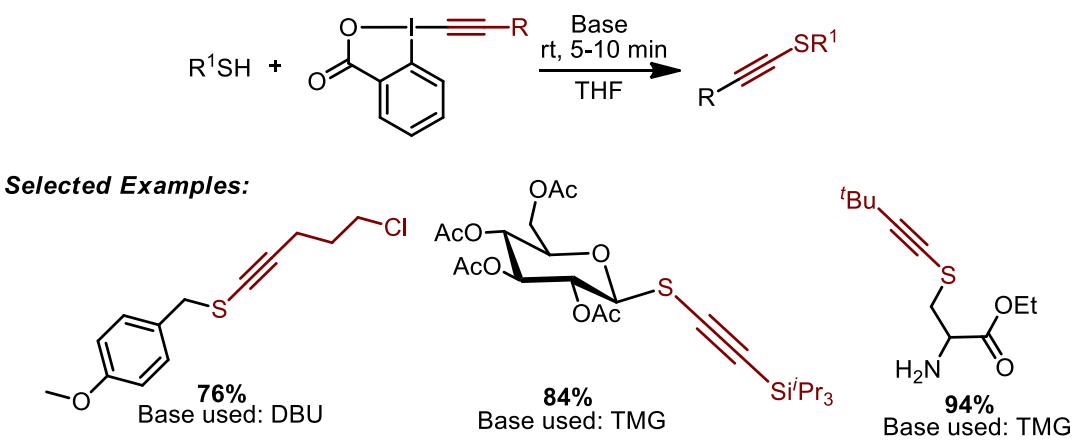

\section{Scheme 4.13}

This reaction is rapid and high-yielding, with high functional group tolerance, leading to compounds with great potential in drug discovery.

In 2014, Reeves et al. ${ }^{51}$ reported a thiol-free synthesis of sulfides, via reaction of Bunte salts ${ }^{52}$ with Grignard reagents. This synthesis avoids the use of malodorous thiols, with the thiol component being an easy-to-handle, non-toxic crystalline solid. Some interesting alkynyl thioethers can be generated from this synthesis in excellent yield (Scheme 4.14).

$$
\mathrm{R}^{1}=-\mathrm{MgCl}+\mathrm{R}^{2} \cdot \mathrm{S}_{\mathrm{SO}_{3} \mathrm{Na}} \underset{0^{\circ} \mathrm{C} \text { to rt }}{\mathrm{THF}}-\mathrm{R}^{1}=-\mathrm{SR}^{2}
$$

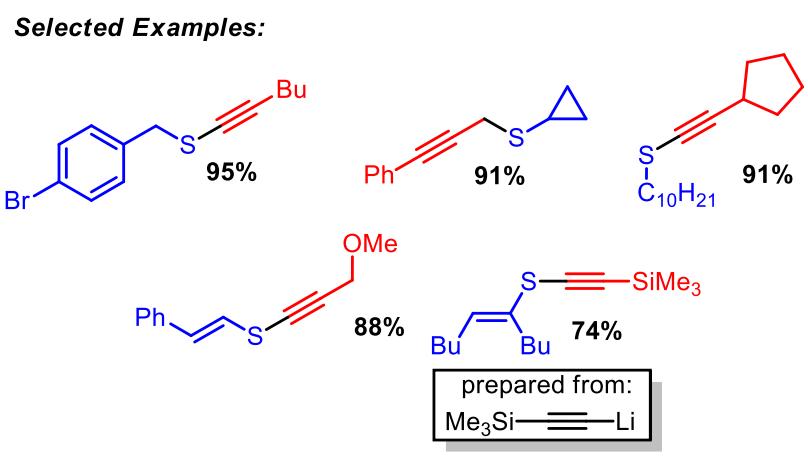

Scheme 4.14

\subsection{Applications of Alkynyl Thioethers}

Given the paucity of reliable synthetic routes towards alkynyl thioethers, it is of no surprise that their reactivity has not been explored in-depth. In the same way as ynol ethers, with their degree of 
unsaturation and functionality, these compounds have enormous potential to be versatile synthetic intermediates, and, given the polarised nature of the alkyne fragment, can be employed in regioselective transformations yielding an array of interesting compounds. A brief overview of the chemistry of these fascinating compounds is given in the sections that follow.

\section{Pd and Cu-Mediated Reactions}

In 2001, Srogl and Liebskind et al. reported ${ }^{53}$ new methodology for the synthesis of substituted alkynes from alkynyl thioethers and boronic acids via a copper carboxylate-mediated, palladium-catalysed thioalkyne-boronic acid cross-coupling. Quite remarkably, this reaction requires no base and works well under mild conditions (in particular at relatively low temperatures) and is an umpolung complement to the Sonogashira reaction. Both aryl and alkenyl boronic acids are employed in the reaction to give a wide range of substituted alkynes (Scheme 5.0).
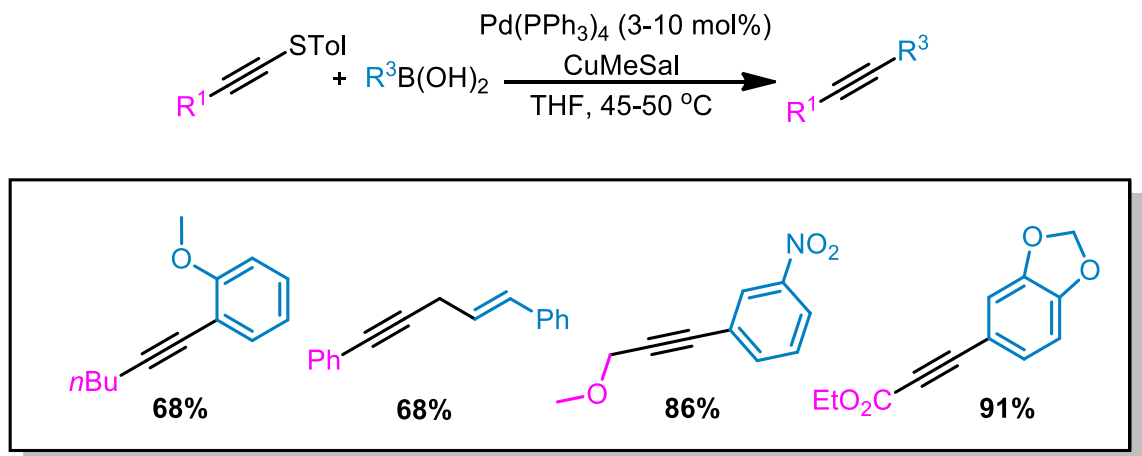

\section{Scheme 5.0}

Following up this work in 2011, Srogl et al. reported a $\mathrm{Pd}^{2+}$ and $\mathrm{Cu}^{2+}$ catalysed oxidative cross-coupling of mercaptoacetylenes and arylboronic acids ${ }^{54}$, yielding aryl thioethers and an aryl alkyne. This reaction is advantageous as two potentially useful compounds are formed, rather than one of them being an unwanted by-product (Scheme 5.1). 


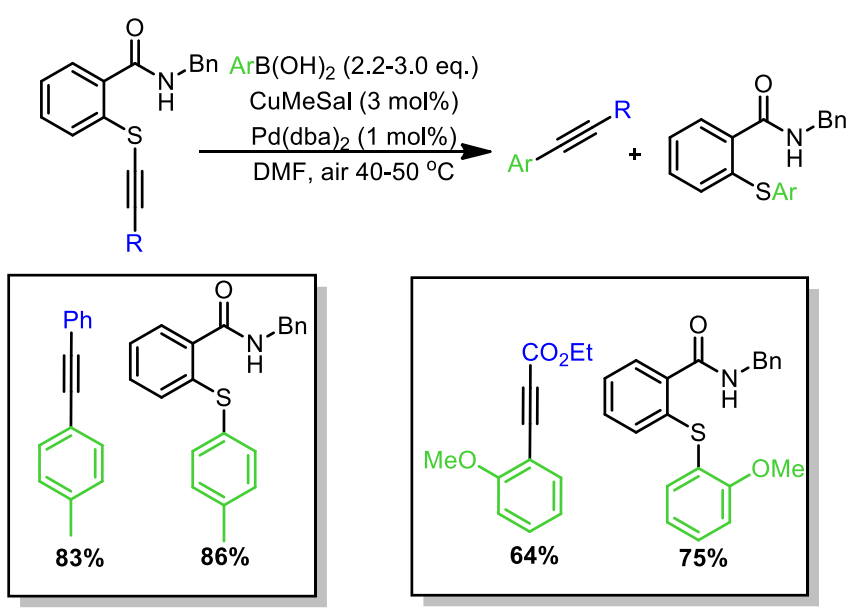

\section{Scheme 5.1}

Pleasingly, the reaction can be executed in air at mild temperatures, allowing for a range of alkynes and aryl thioethers to be synthesised.

In a further development to this chemistry, Knochel et al. reported ${ }^{55,56}$ that organozinc reagents could be used instead of the boronic acids. In this synthesis the relatively cheaper $\mathrm{Pd}(\mathrm{OAc})_{2}$ is used rather than $\mathrm{Pd}\left(\mathrm{PPh}_{3}\right)_{4}$. Both syntheses use the same mild temperatures and take approximately the same time (ca $10 \mathrm{~h}$ ) to reach completion (Scheme 5.2).

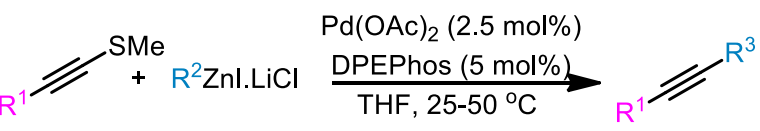

Selected Examples:

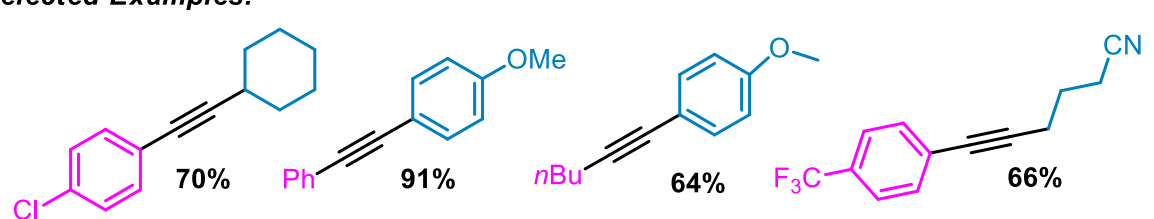

Scheme 5.2

It is also clear that this reaction possesses good substrate scope. Both electron withdrawing and donating groups are tolerated on either side of the triple bond as well as aliphatic groups.

Hilt et al. ${ }^{57,58}$ disclosed a mild [4+2] cycloaddition reaction with unactivated alkynyl thioethers and alkenes in the presence of a cobalt(II) catalyst. Given the fact that sulfur can coordinate transition metals, a greater concentration of the catalyst was required in order for the reaction to reach completion. The intermediate dihydro compounds can be easily oxidised to the aryl thioethers in good yield with DDQ. (Scheme 5.3) 


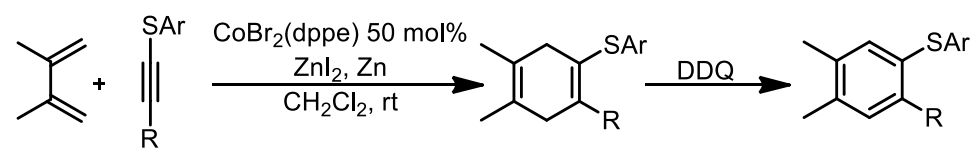

Selected Examples:<smiles>Cc1ccc([18OH])c([SbH])c1</smiles><smiles>Cc1cc(Sc2ccccc2)c(-c2ccccc2)cc1C</smiles><smiles>CC(=O)c1ccc(Sc2ccc(C)c(C)c2)cc1</smiles>

\section{Scheme 5.3}

In the lanthanide series, $\mathrm{Yb}(\mathrm{OTf})_{3}$ was found to be an effective cycloaddition catalyst in the synthesis of $\delta$-thiolactams ${ }^{59}$ via an aza-Diels Alder reaction (Scheme 5.4). The reaction proceeds via an intriguing bis-thioketene intermediate as outlined in Scheme 5.4.

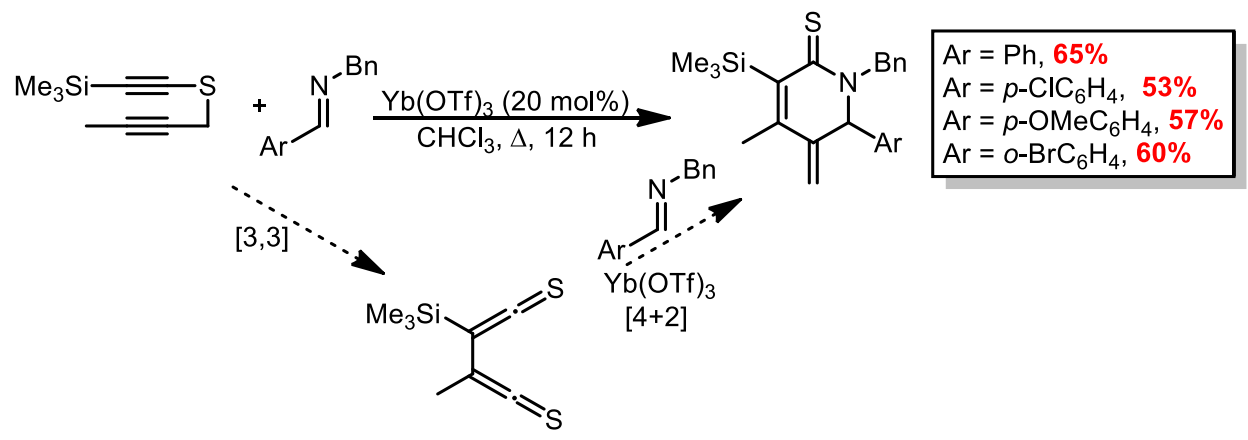

\section{Scheme 5.4}

This reaction produced a range of substituted $\delta$-thiolactams in fair yield which could be further transformed into the Brazilian alkaloid Onychine (Scheme 5.5), highlighting the ability of this chemistry to generate complex molecular frameworks, including natural products in an efficient manner.

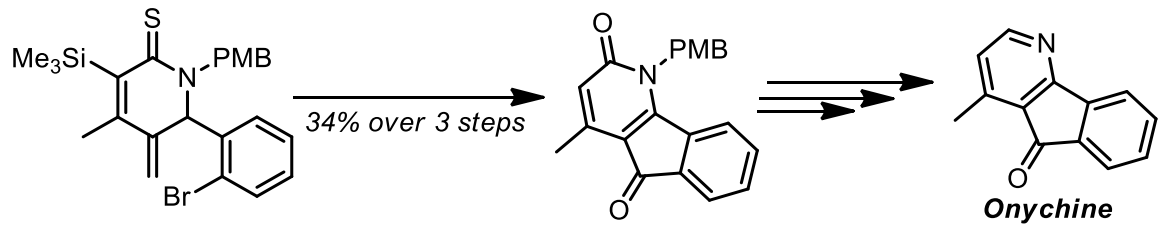

\section{Scheme 5.5}

Jia and Sun et al. have shown ${ }^{60}$ that alkynyl thioethers serve as excellent reactive partners in the Huisgen 1,3-dipolar azide-alkyne cycloaddition. Using an iridium catalyst along with a range of azides, a selection of triazoles can be rapidly synthesised in high yield, with excellent regioselectivity. Incorporation of both the triazole and thioether linkage has the potential to lead to some highly active antifungal agents (Scheme 5.6) 


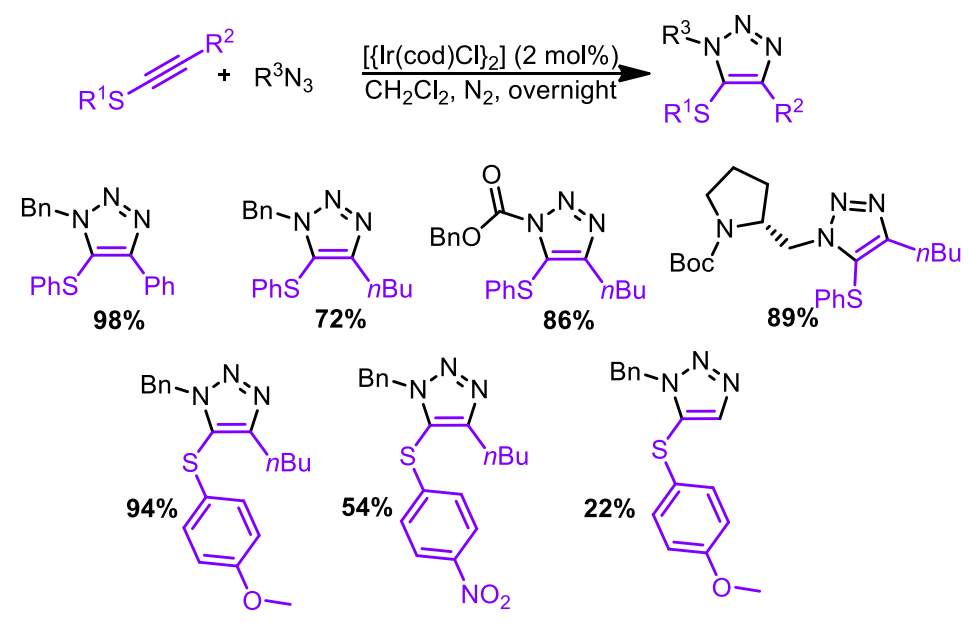

Scheme 5.6

The products can then be oxidised using $m$ CPBA to form 5-sulfonyltriazoles in a totally regioselective manner.

Tam et al. have reported ${ }^{61}$ a ruthenium-catalysed [2+2] cycloaddition of alkynyl thioethers and strained bicyclic alkenes, giving solely the exo-product is good yield. The adducts formed can be futher transformed via desulfonylation or treatment with $m C P B A$ and an organolithium reagent to generate quite complex chiral hydrocarbons expeditiously and in good yield (Scheme 5.7).

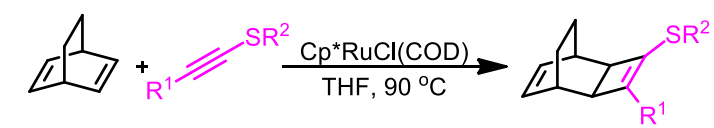

Selected Cycloaddition Adducts:

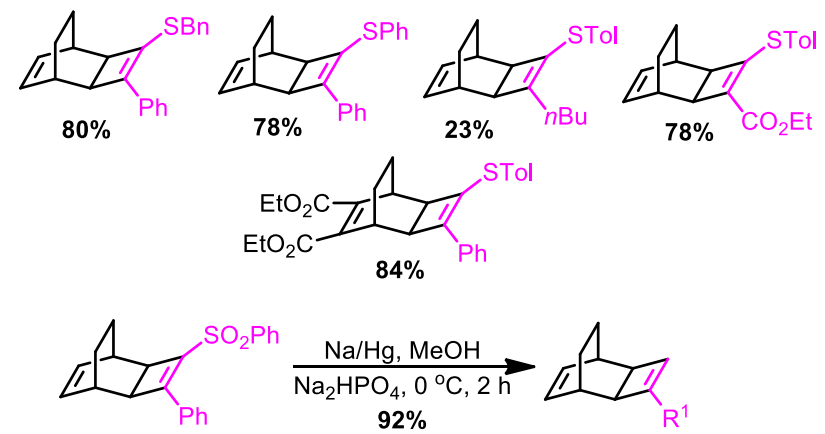

Scheme 5.7

Alkynyl thioethers have also been shown to undergo syn-addition with tributyltin hydride to yield very useful alkenylstannanes which can be used in a number of further transformations. Magriotis et al. reported a highly regio- and stereoselective hydrostannylation of a range of alkynyl thioethers in $1991^{62}$. This very useful reaction is rapid and is complete within minutes at room temperature, yielding a range of useful compounds (Scheme 5.8). 


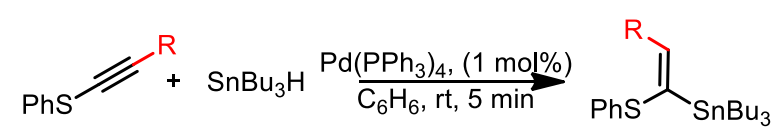

Selected Examples:

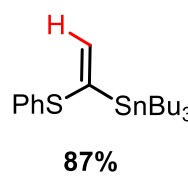

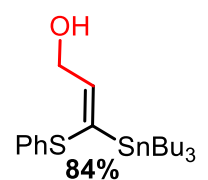

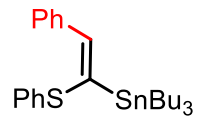

$75 \%$

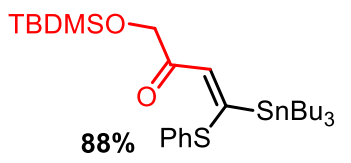<smiles>[10BH2]/C([18OH])=C/C</smiles>

\section{Scheme 5.8}

Based on these findings, Cai et al. ${ }^{63}$ reported a one-pot hydrostannylation-Stille coupling reaction to generate a range of (Z)- $\alpha$-arylthio- $\alpha, \beta$-unsaturated ketones. Both electron donating and withdrawing substituents are tolerated on the acyl chloride although, disappointingly, aliphatic acyl chlorides do not react under the given conditions (Scheme 5.9).

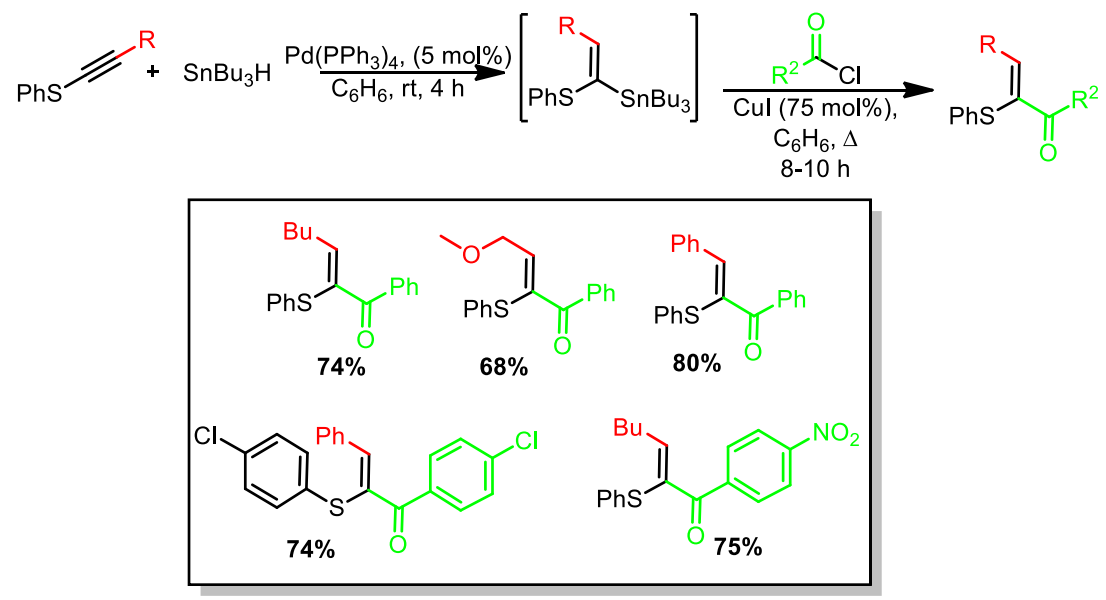

\section{Scheme 5.9}

Similarly, Zhu et al. recently reported ${ }^{64}$ a hydrohalogenation across the alkynyl thioether triple bond to form (E)- $\alpha$-halo vinyl sulfides and consequently exploiting them for accessing stereodefined trisubstituted alkenes. They reasoned that given the polarised nature of the $\mathrm{C}-\mathrm{C}$ triple bond in an alkynyl thioether due to the sulfur atom, controlling the regioselectivity of the addition should be much easier as one carbon atom will be more positively charged than the other allowing for a syn-addition overall (Scheme 5.10). 


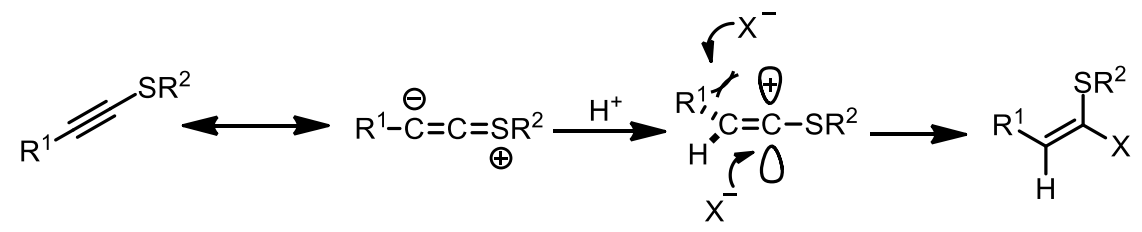

Scheme 5.10

Performing the hydrohalogenation at room temperature was found to be optimal and a single regioisomer could be isolated in high yield (Scheme 5.11). Unlike the analogous (E)- $\alpha$-halo vinyl ethers, these compounds are stable to column chromatography.

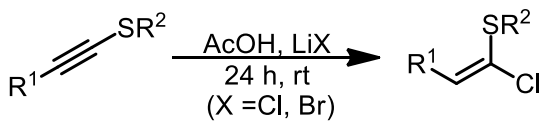

\section{Examples:}
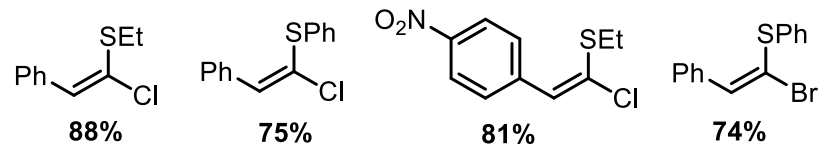

Scheme 5.11

With these (E)- $\alpha$-halo vinyl sulfides at hand, a range of well-known transition metal cross-coupling reactions could be carried out i.e. Suzuki, Sonogashira and Negishi reactions, allowing for the otherwise difficult synthesis of stereo-defined, trisubstituted alkenes (Scheme 5.12).

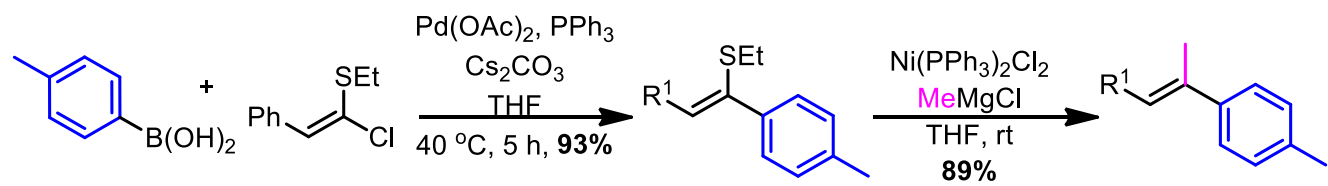

Scheme 5.12

\subsection{Concluding remarks}

In summary, it has been shown that both ynol ethers and alkynyl thioethers are highly versatile molecules in various branches of organic chemistry. When we embarked on this review, our intention was to 'compare and contrast' the reactivity of these molecules given their similarity in structure. In writing this review however, it soon became clear to us that the differences between the two classes of compounds far outweigh the similarities and we decided therefore that considering them separately would be more useful. Nevertheless, the important point remains that both ynol ethers and their sulfur analogues exhibit fascinating reactivity profiles which allow a variety $\mathrm{C}-\mathrm{C}$ bond forming 
processes to occur under relatively mild conditions, offering access to a range of molecules that would be otherwise challenging to prepare. Although straightforward syntheses of both types of molecule have historically been somewhat lacking, the past ten years have shown a steady rise in the number of routes towards both compound classes. Given the high degree of functionality within these species and their unique reactivity profiles, we expect that their popularity for effecting otherwise cumbersome transformations will continue to grow in years to come.

\subsection{Acknowledgements}

The authors gratefully acknowledge the EPSRC (grant reference EP/M02220X/1), Leverhulme Trust, GlaxoSmithKline and University College London for generous financial support of their work.

\subsection{Notes and references}

\footnotetext{
${ }^{1}$ P.J. Stang, V.V. Zhdankin, The Chemistry of Triple Bonded Functional Groups (Ed. S. Patai), Ch. 19, Wiley Interscience, Chichester, 1994, p.1151.

${ }^{2}$ T. Minehan, Acc. Chem. Res., 2016, 49, 1168.

${ }^{3}$ L. Hu, Q. Gui, X. Chen, Z. Tan. G. Zhu, J. Org. Chem., 2016, 81, 4861.

${ }^{4}$ Moyano, F. Charbonnier, A.E. Greene, J. Org. Chem., 1987, 52, 2919.

${ }^{5}$ A. Löffler, G. Himbert, Synthesis, 1992, 495.

${ }^{6}$ K. Tanaka, S. Shiraishi, N. Ishikawa, T. Nakai, Tetrahedron Lett., 1978, 19, 3103.

${ }^{7}$ J.R. Sosa, A.A. Tudjarian, T.G. Minehan, Org. Lett., 2008, 10, 5091.

${ }^{8}$ M.A. Pericàs, F. Serratosa, E. Valentí, Tetrahedron, 1987, 43, 2311.

${ }^{9}$ K. Jouvin, A. Bayle, F. Legrand, G. Evano, Org. Lett., 2012, 14, 1652.

${ }^{10}$ V.J. Gray, B. Slater, J.D. Wilden, Chem. - Eur. J., 2012, 18, 15582

${ }^{11}$ V.J. Gray, J. Cuthbertson, J.D. Wilden, J. Org. Chem., 2014, 79, 5869.

${ }^{12}$ L. Marzo, A. Parra, M. Frías, J. Alemán, J.L. García Ruano, Eur. J. Org. Chem., 2013, 4405

${ }^{13}$ M.A. Pericàs, F. Serratosa, E. Valentí, Synthesis, 1985, 1118.

${ }^{14}$ W. Zhang, J.M. Ready, Angew. Chem., Int. Ed., 2014, 53, 8980.

15 J. S. Alford and H. M. L. Davies, J. Am. Chem. Soc., 2014, 136, 10266

${ }^{16}$ C. Verrier, S. Carret, J.-F. Poisson, Org. Lett., 2012, 14, 5122.

${ }^{17}$ C. Verrier, S. Carret and J.-F. Poisson, Org. Biomol. Chem., 2014, 12, 1875

${ }^{18}$ V. Tran, T.G. Minehan, Org. Lett., 2011, 13, 6588
} 
${ }^{19}$ A. Christopher, D. Brandes, S. Kelly, T.G. Minehan, Org. Lett., 2006, 8, 451

${ }^{20}$ V. Tran, T.G. Minehan, Org. Lett., 2012, 14, 6100

${ }^{21}$ X.Y. Mak, R.P. Ciccolini, J.M. Robinson, J.W. Tester, R.L. Danheiser, J. Org. Chem., 2009, 74, 9381

${ }^{22}$ C. Henry, D. Bolien, B. Ibanescu, S. Bloodworth, D.C. Harrowven, X. Zhang, A. Craven, H.F. Sneddon, R.J. Whitby, Eur. J. Org. Chem., 2015, 1491

${ }^{23}$ H. Cai, Z. Yuan, W. Zhu, G. Zhu, Chem. Commun., 2011, 47, 8682

${ }^{24}$ W. Kong, M. Mao, G. Zhu, Chem. Commun., 2013, 49, 7650

${ }^{25}$ W. Cui, M. Mao, Z. He, G. Zhu, J. Org. Chem., 2013, 78, 9815

${ }^{26}$ M. Satoh, N. Miyaura, A. Suzuki, Synthesis, 1987, 373

${ }^{27}$ M.H. Babu, V. Dwivedi, R. Kant, M.S. Reddy, Angew., Chem., Int., Ed., 2015, 54, 3783

${ }^{28}$ L. Hu, C. Che, Z. Tan, G. Zhu, Chem. Commun., 2015, 51, 16641

${ }^{29}$ X. Qi, J.M. Ready, Angew. Chem. Int. Ed., 2008, 120, 7070

${ }^{30}$ Y. Minami, M. Kanda, T. Hiyama, Chem. Lett., 2014, 43, 181

${ }^{31}$ W. Zhao, H. Qian, Z. Li, J. Sun, Angew. Chem., Int. Ed., 2015, 54, 10005

${ }^{32}$ C.J. Kowalski, K.W. Fields, J. Am. Chem. Soc., 1981, 104, 321

${ }^{33}$ A.W. Hoffmann, Ber., 1881, 14, 2725

${ }^{34}$ F. Arndt, B. Eistert, Ber. Dtsch. Chem. Ges., 1935, 68, 200

${ }^{35}$ M. Julia, V.P. Saint-Jalmes, J-N. Verpeaux, Syn. Lett., 1993, 233

${ }^{36}$ M. Shindo, Y. Sato, K. Shishindo, J. Am. Chem. Soc., 1999, 121, 6507

${ }^{37}$ Kabanyane, S. T.; MaGee, D. I., Can. J. Chem., 1992, 70, 2758

${ }^{38}$ N. Riddell, W. Tam, J. Org. Chem., 2006, 71, 1934

${ }^{39}$ N. Miyachi, M. Shibasaki, J. Org. Chem., 1990, 55, 1975

${ }^{40}$ A.L. Braga, A. Reckziegel, P.H. Menezes, H.A. Stefani, Tetrahedron Lett., 1993, 34, 393

${ }^{41}$ Y. Yang, W. Dong, Y. Guo, R.M. Rioux, Green Chem., 2013, 15, 3170

${ }^{42}$ R.M. Chowdhury, J.D. Wilden, Org. Biomol. Chem., 2015, 13, 5859

${ }^{43}$ V.J. Gray, J. Cuthbertson, J.D. Wilden, J. Org. Chem., 2014, 79, 5869

${ }^{44}$ H. Takeda, S. Shimada, S. Ohnishi, F. Nakanishi, H. Matsuda, Tetrahedron Lett., 1998, 39, 3701

${ }^{45}$ W. Zheng, F. Zheng, Y. Hong, L. Hu, Heteroatom Chemistry, 2012, 23, 105 
${ }^{46}$ C. Chen, L. Chu, F.-L. Qing, J. Am. Chem. Soc., 2012, 134, 12454

${ }^{47}$ I. Ruppert, K. Schlich, W. Volbach, Tetrahedron Lett., 1984, 25, 2195

${ }^{48}$ X. Shao, C. Xu, L. Lu, Q. Shen, J. Org. Chem., 2015, 80, 3012

${ }^{49}$ Z. Ni, S. Wang, H. Mao, Y. Pan, Tetrahedron Lett., 2012, 53, 3907

${ }^{50}$ R. Frei, M.D. Wodrich, D.P. Hari, P-A. Borin, C. Chauvier, J. Waser, J. Am. Chem. Soc., 2014, 136, 16563

${ }^{51}$ J.T. Reeves, K. Camara, Z.S. Han, Y. Xu, H. Lee, C.A. Busacca, C.H. Senanayake, Org. Lett., 2014, 16, 1196

${ }^{52}$ H. Bunte, Chem. Ber., 1874, 646

${ }^{53}$ C. Savarin, J. Srogl, L.S. Liebeskind, Org. Lett., 2001, 3, 91

${ }^{54}$ A. Henke, J. Srogl, Chem. Commun., 2011, 47, 4282

${ }^{55}$ L. Melzig, J. Stemper, P. Knochel, Synthesis, 2010, 12, 2085

${ }^{56}$ L. Melzig, A. Metzger, P. Knochel, Chem. Eur. J., 2011, 17, 2948

${ }^{57}$ G. Hilt, S. Lüers, K. Harms, J. Org. Chem., 2004, 69, 624

${ }^{58}$ G. Hilt, S. Lüers, Synthesis, 2003, 1784

${ }^{59}$ S. Aoyagi, S. Ohata, K. Shimada, Y. Takikawa, Syn. Lett., 2007, 615

${ }^{60}$ S. Ding, G. Jia, J. Sun, Angew. Chem. Int. Ed., 2014, 53, 1877

${ }^{61}$ N. Riddell, W. Tam, J. Org. Chem., 2006, 71, 1934

${ }^{62}$ P.A. Magriotis, J.T. Brown, M.E. Scott, Tetrahedron Lett., 1991, 32, 5047

${ }^{63}$ S. You, W. Hao, M. Cai, Synth, Commun., 2010, 40, 1830

${ }^{64}$ Z. Yang, X. Chen, W. Kong, S. Xia, R. Zheng, F. Luo, G. Zhu, Org. Biomol. Chem., 2013, 11, 2175 